\title{
RESEARCH
}

Open Access

\section{Pre-clinical characterisation of E2814, a high-affinity antibody targeting the microtubule-binding repeat domain of tau for passive immunotherapy in Alzheimer's disease}

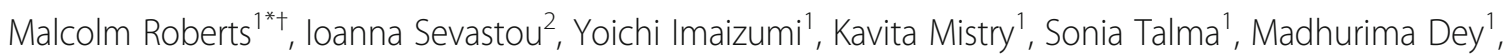
Jane Gartlon ${ }^{1}$, Hiroshi Ochiai ${ }^{3}$, Zhi Zhou ${ }^{3}$, Shigeru Akasofu', Naoki Tokuhara ${ }^{3}$, Makoto Ogo ${ }^{3}$, Muneo Aoyama ${ }^{3}$, Hirofumi Aoyagi ${ }^{3}$, Kate Strand ${ }^{2}$, Ezat Sajedi ${ }^{2}$, Kishan Lal Agarwala ${ }^{3}$, Jared Spidel ${ }^{4}$, Earl Albone ${ }^{4}$, Kanta Horie $^{3}$, James M. Staddon ${ }^{1}$ and Rohan de Silva ${ }^{2^{*+}}$ (D)

\begin{abstract}
Tau deposition in the brain is a pathological hallmark of many neurodegenerative disorders, including Alzheimer's disease (AD). During the course of these tauopathies, tau spreads throughout the brain via synaptically-connected pathways. Such propagation of pathology is thought to be mediated by tau species ("seeds") containing the microtubule binding region (MTBR) composed of either three repeat (3R) or four repeat (4R) isoforms. The tau MTBR also forms the core of the neuropathological filaments identified in AD brain and other tauopathies. Multiple approaches are being taken to limit tau pathology, including immunotherapy with anti-tau antibodies. Given its key structural role within fibrils, specifically targetting the MTBR with a therapeutic antibody to inhibit tau seeding and aggregation may be a promising strategy to provide disease-modifying treatment for AD and other tauopathies. Therefore, a monoclonal antibody generating campaign was initiated with focus on the MTBR. Herein we describe the pre-clinical generation and characterisation of E2814, a humanised, high affinity, $\operatorname{lgG}_{1}$ antibody recognising the tau MTBR. E2814 and its murine precursor, 7G6, as revealed by epitope mapping, are antibodies bi-epitopic for 4R and mono-epitopic for 3R tau isoforms because they bind to sequence motif HVPGG. Functionally, both antibodies inhibited tau aggregation in vitro. They also immunodepleted a variety of MTBR-containing tau protein species. In an in vivo model of tau seeding and transmission, attenuation of deposition of sarkosyl-insoluble tau in brain could also be observed in response to antibody treatment. In AD brain, E2814 bound different types of tau filaments as shown by immunogold labelling and recognised pathological tau structures by immunohistochemical staining. Tau fragments containing HVPGG epitopes were also found to be elevated in AD brain compared to PSP or control. Taken together, the data reported here have led to E2814 being proposed for clinical development.
\end{abstract}

Keywords: Tau, Alzheimer, tauopathy, immunotherapy, neurodegeneration

\footnotetext{
*Correspondence: Malcolm_Roberts@eisai.net; r.desilva@ucl.ac.uk

${ }^{\dagger}$ Dr Malcolm Roberts and Prof Rohan de Silva contributed equally to this work.

'Hatfield Research Laboratories, Eisai Limited, Hatfield, UK

${ }^{2}$ Reta Lila Weston Institute \& Department of Clinical and Movement

Neurosciences, UCL Queen Square Institute of Neurology, 1 Wakefield Street,

London, UK

Full list of author information is available at the end of the article
}

(c) The Author(s). 2020 Open Access This article is distributed under the terms of the Creative Commons Attribution 4.0 International License (http://creativecommons.org/licenses/by/4.0/), which permits unrestricted use, distribution, and reproduction in any medium, provided you give appropriate credit to the original author(s) and the source, provide a link to the Creative Commons license, and indicate if changes were made. The Creative Commons Public Domain Dedication waiver (http://creativecommons.org/publicdomain/zero/1.0/) applies to the data made available in this article, unless otherwise stated. 


\section{Introduction}

Tauopathies are a group of diverse, age-associated neurodegenerative disorders that are neuropathologically characterised by various neuronal and glial inclusions of abnormally hyperphosphorylated, insoluble and fibrillar tau protein [31]. These diseases include Alzheimer's disease $(\mathrm{AD})$, the most common neurological disorder, as well as the parkinsonian primary tauopathies, progressive supranuclear palsy (PSP) and corticobasal degeneration (CBD). Currently, only symptomatic treatments are available for $\mathrm{AD}$, giving rise to a huge unmet clinical need for new therapies to slow down or, better, halt progression of the disease.

$\mathrm{AD}$ is pathologically defined by extracellular amyloid plaques consisting of $A \beta$ peptide fragments, derived from the $\beta$-amyloid precursor protein (APP), and intraneuronal tau inclusions in the form of neurofibrillary tangles (NFTs) and neuropil threads. Extensive autopsy studies [61] have contributed to the current hypothesis that amyloidosis precedes and accelerates neocortical tau pathology, which together contribute to cognitive decline in $\mathrm{AD}$ [39]. Furthermore, $A \beta$ pathology generally occurs years, if not decades, prior to onset of clinical symptoms, posing considerations for therapeutic intervention. Early work by Braak and colleagues showed tau pathology burden and distribution better reflected disease severity, progression and cognitive decline compared with the initiating amyloid load [8]. In more recent years, it has emerged that the different tauopathies are initiated by distinct pathological molecular triggers allowing release of abnormal tau conformers ("seeds") as agents of intercellular propagation of tau pathology. Following tau deposition, neuronal malfunction and death ensue, leading to clinical progression of disease [20].

Tau is a multifunctional protein with a primary role of mediating assembly and stability of axonal microtubules (MTs) [13]. Six isoforms of tau protein are expressed in healthy adult human brain as a result of alternative splicing. These isoforms contain 0,1 , or $2 \mathrm{~N}$-terminal inserts and, through splicing of exon 10, 3 (3R-tau) or 4 (4R-tau) imperfect repeat sequences [34, 40, 41, 50, 75] which constitute the microtubule-binding region (MTBR) in the carboxyhalf of the protein (Fig. 1). Two related hexapeptide motifs, PHF6* $^{*}{ }_{275}$ VQIINK $_{280}$; numbering according to 2N4R-tau isoform; Accession Code: NP_005901.2) and PHF6 ( ${ }_{306}$ VQIVYK $_{311}$ ), located within the second-(R2) and third (R3) MT-binding repeat domains respectively (Fig. 1), are necessary for the pathological aggregation of tau [47, 77, 78]. These short motifs are hydrophobic with a high propensity for $\beta$-sheet structure formation $[68,70]$. The different 3R- and 4R-tau isoforms are thought to play an important role in pathology, with the composition of tau aggregates varying between different tauopathies. AD has approximately equal amounts of 3R- and 4R-tau contained within pathological structures whereas other tauopathies, such as corticobasal degeneration (CBD) or Pick's disease exhibit, respectively, predominantly $4 \mathrm{R}$ - or 3R-tau pathology (for review, see [18]).

During the course of disease, tau becomes hyperphosphorylated and released from MTs, resulting in a conformational conversion of tau from its highly soluble, natively unfolded state to the insoluble fibrillar aggregates by way of oligomeric intermediates [29]. Pathological conformers of tau (the "seeds") can, on contact, facilitate the templated conversion of normal soluble tau into pathological conformers, leading to a cascade-like amplification and spread of pathology [49]. Functional tau seeds require an intact MTBR [22]. This region also forms the proteaseresistant core of the terminal filamentous deposits [26], highlighting the importance of the MTBR in disease. Furthermore, many cases of familial frontotemporal dementia (FTD) have causative missense mutations in the tau gene (MAPT) that result in coding changes in amino acids predominantly clustered around the tau MTBR, reducing MT-binding capacity and leading to a greater propensity of tau to aggregate [78]. Transmissible seeds have also been reported to spread transsynaptically to neighbouring neurons via interconnected pathways, leading to the hierarchical propagation of tau pathology in disease-specific patterns $[9,69]$. Effective ways of slowing or halting tau disease progression may therefore be through prevention of either pathological conversion of tau into functional seeds or blocking inter-cellular spread of tau protein conformers that contain the MTBR.

The precise molecular nature of the MTBR-containing seed that transmits from cell to cell is unknown. It has been suggested that seeds are oligomers or short fibrils as opposed to higher-order assemblies [44]. However, recent work has shown monomeric seed-competent tau could be isolated from AD brain [57]. This seed-competent tau differs in intramolecular interactions when compared to inert, soluble monomeric tau; it is predicted that such interactions could expose the two PHF6 motifs that are otherwise buried in the soluble tau [57]. Conversely, the PHF6 motifs in inert tau are predicted to be shielded by a preferential hairpin conformation around this region making them less prone to aggregation [57].

The possibility that toxic tau seeding species containing the MTBR are extracellular and transmissible in human brain opens up the prospect of therapeutic intervention through immunotherapy. Since the first preclinical report of active immunisation in transgenic mice [5], this area of tau research has received increasing attention. Several passive and active immunotherapies targeting either different regions of the tau protein, pathological conformation, phospho-epitopes, oligomeric or aggregated tau have been described, with some now in early-stage clinical trials (for reviews see $[14,45])$. Since the MTBR of tau plays such an 


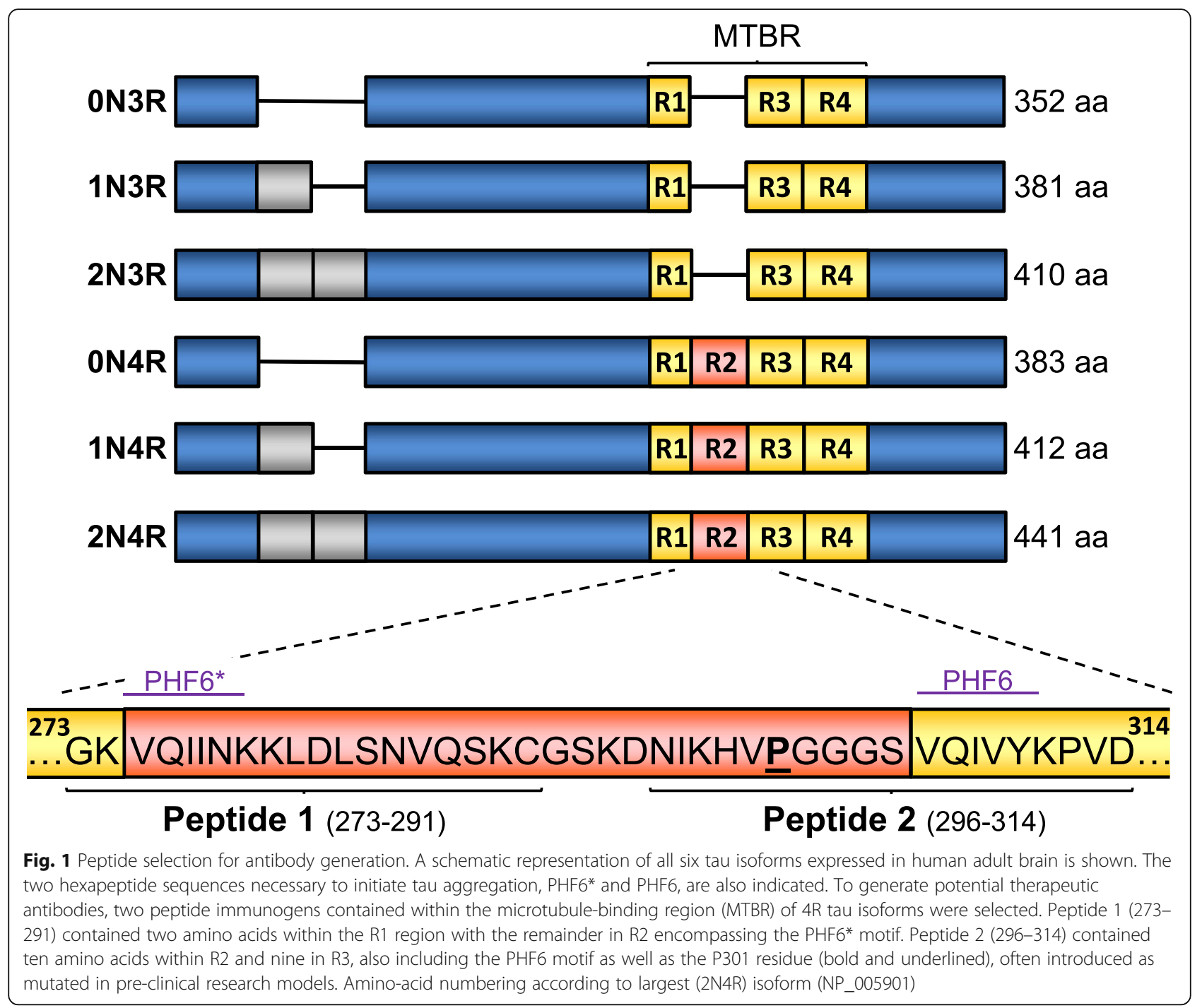

important role in forming functional seeds as well as being structurally key and integral to the core of the end stage fibrils, we decided to generate therapeutic antibodies against that region. In order to prevent seeding and the adoption of filament-forming structures within tau, we therefore sought to identify antibodies that could precisely target and mask the MTBR PHF6 motifs and/or flanking inter-repeat regions necessary for conformational conversions and aggregation. The goal was to identify antibodies that may prevent tau becoming seed-competent. Such agents could slow the initiation or progression of pathological tau formation rather than specifically recognise later-stage pathological conformations. E2814 is described here as a humanised, bi-epitopic, high affinity antibody specifically binding the HVPGG sequences within R2 and $\mathrm{R} 4$ of the tau MTBR. R2 is present only in 4R-tau isoforms, directly adjacent to the PHF6 domain in R3. The creation and preclinical development of E2814 based on its murine precursor, 7G6 is described in this report.
Clinical trials to evaluate the safety, tolerability and efficacy of E2814 in human subjects have been initiated.

\section{Materials and methods}

\section{Nomenclature}

Tau isoforms with three or four microtubule-binding repeats are designated: 3R-tau and 4R-tau, respectively. The repeats are labelled, starting from the N-terminal side: R1, R2, R3 and R4 (Fig. 1).

\section{Animals}

Animal care and experimental procedures were performed in an animal facility accredited by the Health Science Center for Accreditation of Laboratory Animal Care and Use of the Japan Health Sciences Foundation. All protocols were approved by the Institutional Animal Care and Use Committee and carried out in accordance with, as appropriate, the Animal Experimentation Regulations of Eisai Co., Ltd or Cell Engineering Corporation. 


\section{Postmortem brain}

Post-mortem fixed and frozen brain samples were obtained from the Queen Square Brain Bank for Neurological Disorders, (UCL Queen Square Institute of Neurology, London). Ethical approval for the study was obtained from the Local Research Ethics Committee of the National Hospital for Neurology and Neurosurgery, London, UK. Tissue was stored for research purposes under license 12,198 from the Human Tissue Authority, UK.

\section{Antibody generation and purification}

All original mouse hybridomas were generated by Cell Engineering Corporation (Osaka, Japan). Based on tau sequence, Peptide 1 ( ${ }_{273}$ GKVQIINKKLDLSNVQSKC ${ }_{291}$; numbering according to 2N4R (441 amino-acids)) and Peptide 2 ( ${ }_{296}$ NIKHVPGGGSVQIVYKPVD $\left._{314}\right)$ (Fig. 1) were selected, synthesised (with an N-terminal cysteine added to Peptide 2 for coupling) and coupled to keyhole limpet hemocyanin (KLH) using m-maleimidobenzoylN-hydroxysuccinimide ester (MBS) chemistry. Peptideconjugated KLH was then mixed with Freund's complete adjuvant $(1: 2 \mathrm{v} / \mathrm{v})$, injected into the tailbase of Mapt-null mice (Jackson Labs, 007251) and, 3 weeks later, lymphocytes were isolated from the medial iliac lymph nodes and fused with mouse myeloma SP2 cells. Resulting hybridomas were maintained in growth media: Hybridoma-SFM (Gibco), supplemented with $10 \%$ foetal bovine serum (FBS, Biosera), $1 \mathrm{ng} / \mathrm{mL}$ human IL-6 (R\&D Systems) and $1 \mathrm{x}$ penicillin-streptomycin-amphotericin $\mathrm{B}$ suspension (Wako). Culture supernatants were screened for antibodies using standard or competitive ELISA formats with BSA-conjugated peptide or recombinant wild type 2 N4R tau protein (Enzo Life Sciences). Cultures were serially-diluted to obtain single-cell clones for expansion and cryopreservation. From multiple clones, four of interest were selected that were raised against Peptide 1 and eight against Peptide 2. The 7G6 clone derived from Peptide 2 immunisation was sequenced and selected for further characterisation and humanisation based on its high affinity for recombinant tau protein.

Heavy and light chain human sequences derived from the original 7G6 hybridoma were subcloned into proprietary (Eisai Inc.) mammalian expression vectors and transiently expressed by co-transfection into HEK293 cells using an Expifectamine ${ }^{\mathrm{Ts}} 293$ transfection kit (Thermo Fisher Scientific). All details of antibody humanization are described in patent WO2019077500 wherein E2814 is designated 7G6-HCzu25-LCzu18. Antibodies were purified by Protein-A affinity chromatography, eluted in $100 \mathrm{mM}$ glycine- $\mathrm{HCl}$ ( $\mathrm{pH} 2.9)$ and desalted into formulation buffer ( $25 \mathrm{mM}$ sodium phosphate $\mathrm{pH} 6.5,150 \mathrm{mM} \mathrm{NaCl})$.

\section{Recombinant tau protein production}

All recombinant truncated and full-length tau proteins (other than those used in Additional file 1: Figure S1) were produced in E.coli and purified as described previously [72] with minor modification. Briefly, cDNA encoding tau sequences were subcloned into the $\mathrm{pET} 15 \mathrm{~b}$ vector (Novagen) and transformed into BL21 (DE3) cells (ThermoFisher). Following induction of protein expression, cell pellets were resuspended in $50 \mathrm{mM}$ PIPES pH 6.4, $1 \mathrm{mM}$ EGTA, $1 \mathrm{mM}$ DTT and protease inhibitors. Cells were disrupted through sonication and the clarified lysate was then boiled for $15 \mathrm{~min}$ to allow enrichment of soluble and un-precipitated tau protein in the supernatant. Further purification was performed by ammonium sulfate precipitation, Cellufine ${ }^{\mathrm{TM}}$ phosphate (JNC Corporation) ion exchange chromatography and reverse-phase HPLC.

\section{Antibody affinity determination}

Binding affinities of wild-type recombinant $2 \mathrm{~N} 4 \mathrm{R}$ tau protein for murine 7G6 and human E2814 antibodies were determined by surface plasmon resonance (SPR) using a streptavidin capture method and Biacore $\mathrm{T}^{-100}$ instrument (GE Healthcare). Each antibody was bufferexchanged into $0.1 \mathrm{M}$ sodium bicarbonate $\mathrm{pH} 8.3$ and then biotinylated by incubation with freshly-prepared NHS-PEG4-biotin at a 5:1 M ratio (biotin:antibody) for $1 \mathrm{~h}$ at room temperature. Excess biotin was removed by two sequential buffer exchanges into PBS using $0.5 \mathrm{~mL}$ Zeba SPIN $40 \mathrm{kDa}$ MWCO desalting columns (Thermo Fisher Scientific). Prior to use in the SPR assay, biotinylated antibodies were diluted to $2 \mu \mathrm{g} / \mathrm{mL}$ in PBS containing $0.2 \%$ BSA. Antibodies were injected at a flow rate of $10 \mu \mathrm{L} / \mathrm{min}$ to achieve capture levels of approximately 225 response units (RU) on a prepared CAP chip (with final streptavidin levels of $3500 \mathrm{RU}$ ) from a biotin CAPture kit (GE healthcare). Recombinant wild-type 2N4R tau protein was passed over the antibody-bound chips at concentrations of $0,0.16,0.8,4$ and $20 \mathrm{nM}$. Once kinetic data had been collected, a 1:1 Langmuir model was employed to calculate the association rate, dissociation rate and equilibrium dissociation constants for each biotinylated antibody.

Similarly, the binding affinity and mode of interaction kinetics of the unmodified murine 7G6 antibody for recombinant human 2N4R wild-type and mutant P301S tau were also assessed by SPR but on a Biacore S200 (Molecular Interaction Technology). A protein A/G chip was used to capture the 7 G6 antibody. Sensorgrams were then obtained for the association and dissociation of the varying concentrations of recombinant human $2 \mathrm{~N} 4 \mathrm{R}$ tau ranging from 1.25 to $20 \mathrm{nM}$ for the wild-type and 2.5 to $40.0 \mathrm{nM}$ for the P301S mutant protein. Responses were expressed as RU to represent molecular mass changes on 7 G6 captured by the protein $\mathrm{A} / \mathrm{G}$ during the reaction time course 
(association for $120 \mathrm{~s}$; dissociation for $380 \mathrm{~s}$ ). The association rate, dissociation rate and equilibrium dissociation rate were calculated as described above.

\section{Fine epitope mapping}

Purified murine 7G6 and human E2814 antibodies were epitope-mapped to full length human wild-type tau protein (NCBI reference P10636-8) by PEPperPRINT (Heidelberg, Germany). The tau protein sequence was elongated in silico with a neutral GSGSGSG linker sequence at both the $\mathrm{N}$ and C-termini. Overlapping 15-mer peptides covering the entire in silico elongated sequence were synthesised and then printed in duplicate onto a glass chip. This chip also contained 82 additional spots of an HA-tag control peptide (YPYDVPDYAG). 7G6 and E2814 anti-tau antibodies were diluted to $1 \mu \mathrm{g} / \mathrm{mL}$ in PBS containing $0.05 \%$ Tween-20 and 10\% Rockland blocking buffer (Rockland, MB-070). Each antibody was then incubated separately as described above for $16 \mathrm{~h}$ at $4{ }^{\circ} \mathrm{C}$ with shaking. Primary antibodies were removed and each chip was washed in PBS containing 0.05\% Tween 20. Wash buffer was removed and, as appropriate, secondary antibodies (LI-COR) were added: either (for 7G6) goat antimouse IgG $(\mathrm{H}+\mathrm{L})$ DyLight $^{\mathrm{m}} 680$ (1:5000), or (for E2814) goat anti-human IgG $(\mathrm{H}+\mathrm{L})$ DyLight $^{\mathrm{m}} 680$ (1:5000) together with (for the control peptide) anti-HA tag IgG $\operatorname{DyLight}^{\mathrm{su}} 800$ (1:2000). All secondary antibodies were diluted in the same buffer as primary antibodies and then incubated on chips for $45 \mathrm{~min}$ at room temperature. The secondary detection antibodies were removed and the chips were washed again. Fluorescence images were acquired on the LI-COR Odyssey ${ }^{\text {tw }}$ Imaging System. Microarray data were then analysed using the PepSlide ${ }^{\mathrm{mm}}$ Analyser software.

\section{In vitro tau aggregation}

Prior to inducing tau aggregation, wild-type or P301S recombinant $2 \mathrm{~N} 4 \mathrm{R}$ tau protein was reduced to prevent effects on aggregation through disulphide bond formation [6]. To achieve and maintain thiol reduction, a buffer containing $60 \mu \mathrm{M}$ recombinant tau, $0.5 \mathrm{mM}$ TCEP, 25 $\mathrm{mM}$ HEPES (pH 7.4) and $100 \mathrm{mM} \mathrm{NaCl}$ in a final volume of $20 \mu \mathrm{L}$ was prepared, heated to $98^{\circ} \mathrm{C}$ for $30 \mathrm{~min}$ and cooled to room temperature.

The next step was addition of relevant antibodies or buffer controls. First, the reduced tau protein was diluted by addition of $52 \mu \mathrm{L}$ buffer containing $25 \mathrm{mM}$ HEPES (pH 7.4) and $100 \mathrm{mM} \mathrm{NaCl}$. Then, $1 \mu \mathrm{L}$ of $100 \mathrm{x} \mathrm{HALT}^{\circ}$ protease inhibitor cocktail (Thermo Fisher Scientific) and $25 \mu \mathrm{L}$ of $5 \mathrm{mg} / \mathrm{mL}$ antibody working stock solution (or in some cases $25 \mu \mathrm{L}$ of buffer) were added to the mixture. The mixture was then incubated at $37^{\circ} \mathrm{C}$ for $30 \mathrm{~min}$. Tau aggregation was initiated by addition of $2 \mu \mathrm{L}$ of a $3 \mathrm{mg} / \mathrm{mL}$ heparin stock $(M W \approx 5000$; Thermo Fisher Scientific).
The final reaction components in a total volume of $100 \mu \mathrm{L}$ were: $12 \mu \mathrm{M}$ tau, $0.1 \mathrm{mM}$ TCEP, $1.25 \mathrm{mg} / \mathrm{mL}(8.3 \mu \mathrm{M})$ antibody, $25 \mathrm{mM}$ HEPES (pH 7.4), $100 \mathrm{mM} \mathrm{NaCl}, 1 \mathrm{x}$ HALT $^{\circ}$ Protease Inhibitor cocktail and $0.06 \mathrm{mg} / \mathrm{mL}(\approx$ $12 \mu \mathrm{M})$ heparin. Reactions were maintained at $37^{\circ} \mathrm{C}$ over a period of 6 days after heparin addition.

At required time points, $10 \mu \mathrm{L}$ aliquots of the tau aggregation assay mixture were removed and placed directly into a well of a 384-well plate (781,076, Greiner). Then, $20 \mu \mathrm{L}$ of a $15 \mu \mathrm{M}$ thioflavin S (Sigma) working solution was added to give a final concentration of $10 \mu \mathrm{M}$ in the well. The plate was incubated in the dark for $30 \mathrm{~min}$ at room temperature. Green fluorescence $(485 \mathrm{~nm}$ excitation and $520 \mathrm{~nm}$ emission), indicative of tau aggregation, was measured on a Pherastar ${ }^{\circ}$ plate reader (BMG Labtech).

\section{Cell-based tau seeding assay}

Truncated tau (244-372,'K18') [60] fibrils were generated by mixing recombinant monomeric protein with 2 $\mathrm{mM}$ DTT and $240 \mu \mathrm{g} / \mathrm{mL}$ heparin (Acros) in $100 \mathrm{mM}$ sodium acetate, $\mathrm{pH} 7.0$ at $37^{\circ} \mathrm{C}$ for 48 to $96 \mathrm{~h}$. Aggregates were collected by ultracentrifugation and then resuspended in $100 \mathrm{mM}$ sodium acetate, $\mathrm{pH} 7.0$. The resulting fibrils were sonicated prior to use as seeds. Recombinant 2N4R P301S tau monomer was also used as seed material in separate experiments.

To prepare the immunodepletion samples, the E2814 antibody was used to precipitate fibrillar K18 or monomeric recombinant P301S tau protein using the Immunoprecipitation Dynabeads ${ }^{\bullet}$ Protein G kit (Thermo Fisher Scientific) as per the manufacturer's instructions. Briefly, different amounts of E2814, human IgG1 (BioXCell, BP0297) control antibody or buffer $(25 \mathrm{mM}$ sodium phosphate $\mathrm{pH} 6.5,150 \mathrm{mM} \mathrm{NaCl}$ ) were pre-incubated with $1.5 \mathrm{mg}$ of Dynabeads. Antibody-bound (or buffertreated) beads were resuspended in buffer with or without $0.2 \%$ BSA. Either $300 \mathrm{ng}$ of $\mathrm{K} 18$ fibrils or $30 \mathrm{ng}$ of P301S recombinant tau were added to the bead suspension before mixing head-over-end for $30 \mathrm{~min}$ at room temperature. Following separation of the magnetic beads, unbound material was collected and retained as the immunodepleted sample for use on cells.

Lenti-X $293 \mathrm{~T}$ cells were transiently transfected with the pcDNA3.1(+) vector encoding the human mutant P301S 0N4R tau isoform, using LTX and Plus ${ }^{\mathrm{TM}} \mathrm{Re}-$ agent (Life Technologies) as per manufacturer's recommendation. Cell suspension was dispensed into polyethylenimine-coated 96 well plates ( 0.8 to $1.2 \times$ $10^{3}$ cells/well) in Dulbecco's Modified Eagle's Medium (D-MEM) containing 10\% heat-inactivated FBS. Cells were incubated overnight at $37^{\circ} \mathrm{C}$ under a $5 \% \mathrm{CO}_{2}$ atmosphere. The following day, each sample was diluted into Opti-MEM (Life Technologies). Plated cells were washed twice and left in half the original 
volume of Opti-MEM. An equal volume of diluted immunodepleted sample was added to each well and incubated for $48 \mathrm{~h}$ at $37^{\circ} \mathrm{C}$ under a $5 \% \mathrm{CO}_{2}$ atmosphere. Each experiment was performed in triplicate or quadruplicate. Following a 2 day incubation period, cells were fixed in $4 \%$ paraformaldehyde and stained with Cellstain DAPI solution (1:1000, Dojindo; DAPI diluted in 5\% BSA in TBS) and Thioflavin S (ThS, Thioflavin $\mathrm{S}$ dissolved in 50\% Ethanol to a final concentration of $0.0003 \%$ ). Each well was then washed twice with $50 \%$ ethanol, and then again with purified water prior to imaging the plate. Fluorescent images of each well were obtained on the Opera Phenix High Content Screening System (Perkin Elmer). Numbers of ThS and DAPI-positive signals in each well were analyzed using Harmony High-Content Analysis Software (Perkin Elmer). The seeding effects of samples added to cells were calculated using Microsoft Excel, TIBCO Spotfire software and GraphPad Prism.

\section{Intrahippocampal tau seed injection in mice}

Aggregated recombinant human 2N4R P301S tau seeds were prepared in the same way as described for K18 fibrils used in the cell-based assay. Either $3 \mu \mathrm{L}$ of P301S tau seeds (at $1.5 \mathrm{mg} / \mathrm{mL}$ ) or $100 \mathrm{mM}$ sodium acetate $\mathrm{pH}$ 7.0 (buffer control) was stereotactically injected into the left hippocampus of 3 to 4 month old male MAPT P301S transgenic mice [3]. The rate of seed injection was $0.5 \mu \mathrm{L} / \mathrm{min}$ using an UltraMicroPump III and $\mathrm{Mi}$ cro4 Controller (World Precision Instruments). More than $6 \mathrm{~h}$ prior to intrahippocampal seed administration, mice were injected intraperitoneally with either 7G6 or $\mathrm{IgG}_{2 \mathrm{~b}}$ control (BioXCell, BP0086) antibodies at $40 \mathrm{mg} / \mathrm{kg}$ or vehicle $(25 \mathrm{mM}$ sodium phosphate $\mathrm{pH} 6.5,150 \mathrm{mM}$ $\mathrm{NaCl}$ ). Peripheral dosing at the same levels was performed 1 and 2 weeks following the intrahippocampal seed addition.

One week after the final peripheral antibody or vehicle administration, the animals were sacrificed. Terminal blood was collected for plasma analysis, as well as CSF, before each animal was perfused with saline. Brain tissue was removed and the cortex and hippocampus from each side (ipsilateral and contralateral sides to the seed injection site) were isolated, weighed and immediately frozen in liquid nitrogen before storage at $-80^{\circ} \mathrm{C}$.

To quantify the extent of tau seeding and transmission, levels of sarkosyl-insoluble tau were measured. Sarkosyl (N-lauroylsarcosinate) has been used in tau research for many years to enrich for end-stage fibrils found in human tauopathy brains as well as transgenic mice $[33,35]$. The majority of tau protein in brain is soluble but tau fibrils are insoluble in sarkosyl detergent. Here, dissected brain tissues were homogenized on ice in 19 volumes $(\mathrm{w} / \mathrm{v})$ of extraction buffer containing 50
mM Tris- $\mathrm{HCl}$ (pH 7.5), 5 mM EDTA, 1 mM EGTA, 1\% NP-40, $0.25 \%$ deoxycholic acid sodium salt, $0.1 \mathrm{M} \mathrm{NaCl}$, $0.5 \mathrm{mM}$ PMSF, $1 \mathrm{x}$ PhosSTOP (Roche) and 1x Complete $(\operatorname{EDTA}(-))$ protease inhibitor cocktail (also Roche). Homogenates were centrifuged at $163,000 \times \mathrm{g}$ at $4{ }^{\circ} \mathrm{C}$ for 20 $\mathrm{min}$. The pellet was then resuspended in 10 volumes (original tissue weight/volume) of buffer containing 10 $\mathrm{mM}$ Tris- $\mathrm{HCl}$ (pH 7.5), $0.5 \mathrm{M} \mathrm{NaCl}, 1 \mathrm{mM}$ EGTA, $10 \%$ sucrose and $1 \%$ sarkosyl prior to sonication. Sarkosyltreated samples were incubated at $37^{\circ} \mathrm{C}$ for $60 \mathrm{~min}$ and then centrifuged at $163,000 \times \mathrm{g}$ at $4{ }^{\circ} \mathrm{C}$ for a further 20 min. The final pellet was resuspended in $10 \mathrm{x}$ volumes (original tissue weight/volume) of PBS to constitute the sarkosyl-insoluble fraction.

The amount of tau in the sarkosyl-insoluble fraction was quantified by western blotting. Sarkosyl-insoluble fractions were solubilized in NuPAGE LDS sample buffer (Invitrogen) containing reducing agent and then heated at $80^{\circ} \mathrm{C}$ for $10 \mathrm{~min}$. Proteins were resolved on $12.5 \%$ polyacrylamide gels and then transferred to $0.2 \mu \mathrm{m}$ PVDF membranes (Bio-Rad). Blots were blocked in $2.5 \%$ skimmed milk in TBS containing $0.05 \%$ Tween for $1 \mathrm{~h}$ at room temperature and then probed with the humanspecific monoclonal anti-tau antibody HT7 (1:1000, ThermoFisher Scientific) also for $1 \mathrm{~h}$ at room temperature. Blots were washed and then incubated with an HRP-conjugated, anti-mouse secondary antibody (1:2000, GE Healthcare) for a further hour at room temperature. Tau proteins were detected by addition of chemiluminescent substrate (Merck Millipore) and images captured using the Fusion FX system (Vilber-Lourmat). Bands were quantified by reference to a serial dilution of tau-containing samples on each blot derived from the sarkosyl-insoluble fraction of spinal cord from 8 month old animals of the same transgenic mouse strain. An arbitrary unit (AU) of 1 was defined as the band intensity detected by the HT7 antibody from $7 \mu \mathrm{g}$ of the spinal cord insoluble fraction loaded on the gel.

\section{Immunohistochemistry with E2814}

Immunohistochemistry was performed on fixed, paraffinembedded sections $(8 \mu \mathrm{m})$ from de-identified Alzheimer's disease (AD; frontal cortex; $n=1$ ), progressive supranuclear palsy (PSP; frontal cortex; $n=1$ ) and Pick's disease (PiD; hippocampus; $n=1$ ) cases. The sections were dewaxed using several changes of xylene, followed by washes in several changes of $100 \%$ industrial methylated spirit (IMS) for several minutes each change. Sections were then incubated with hydrogen peroxide $\left(\mathrm{H}_{2} \mathrm{O}_{2}\right)$ in methanol $\left(2 \mathrm{ml} \mathrm{H}_{2} \mathrm{O}_{2}\right.$ per $100 \mathrm{ml}$ methanol) for $10 \mathrm{~min}$ at room temperature to block endogenous peroxidase and then rinsed under running tap water for $10 \mathrm{~min}$. For antigen retrieval, sections were pressure-cooked in citrate buffer $\mathrm{pH} 6$ for $10 \mathrm{~min}$, rinsed under running tap water followed by a rinse in Trisbuffered saline (TBS) solution. To block non-specific 
human-on-human antibody reactivity, staining was performed using the Klear Human HRP-Polymer DAB Detection Kit (D103-18, GBI Labs) as per supplier's protocol with some modifications. On the day before use, E2814 antibody or control human $\mathrm{IgG}_{1}$ antibody (Clone X9G6C80, Eisai Inc.) was diluted in Human Primer (RTU) Reagent at $0.5 \mu \mathrm{g} / \mathrm{mL}, 0.33 \mu \mathrm{g} / \mathrm{mL}$ and $0.2 \mu \mathrm{g} / \mathrm{mL}$ and then mixed gently for $30 \mathrm{~s}$ to $1 \mathrm{~min}$ and stored at $4{ }^{\circ} \mathrm{C}$ overnight. The pre-incubated antibody in Human Primer (RTU) Reagent/antibody mix was raised to room temperature and quenched with $1 \mathrm{x}$ Reagent 2 (Quenching Buffer $5 \mathrm{x}$ ) for 15 to $30 \mathrm{~min}$ at room temperature before placing on ice for no more than 1 h. Prior to primary antibody incubation, sections were blocked for non-specific binding following the supplier's protocol. The antibody in Human Primer (RTU) Reagent/Quenching Buffer was then added to cover each section and incubated for $60 \mathrm{~min}$ at room temperature, followed by three washes in $\mathrm{PBS} / 0.05 \%$ Tween-20. Sections were then incubated with 1:1000 dilution of HRP-conjugated anti-human antibody (sc-2907, SantaCruz) either for $30 \mathrm{~min}$ at room temperature or overnight at $4{ }^{\circ} \mathrm{C}$. For HRP staining, avidin biotin complex (ABC, Dako) was prepared following the manufacturer's instructions. Sections were rinsed three times for $5 \mathrm{~min}$ each in TBS before applying the $\mathrm{ABC}$ working solution to all sections for $30 \mathrm{~min}$ at room temperature. The $\mathrm{ABC}$ solution was removed and tissue was washed again in TBS as before. A DAB working solution ( $1 \mathrm{ml}$ of $5 \%$ DAB in $100 \mathrm{ml}$ TBS) was prepared and activated by adding $\mathrm{H}_{2} \mathrm{O}_{2}$ (32 $\mu \mathrm{L}$ per $100 \mathrm{~mL}$ DAB working solution). Sections were immersed in activated DAB solution for 5 min at room temperature. Finally, the tissue was rinsed in TBS and then extensively under running tap water for $10 \mathrm{~min}$. The sections were counterstained in Mayer's Haematoxylin for $30 \mathrm{~s}$ to $1 \mathrm{~min}$ and then washed again under warm running tap water for approximately $10 \mathrm{~min}$. Sections were dehydrated through ascending grades of IMS (70, 90 and 100\%), cleared in xylene and mounted under DPX medium (Sigma-Aldrich). Microscopy and digital image acquisition of stained sections were carried out on a Nikon Eclipse Ni Microscope and images processed using Adobe Photoshop'.

\section{Sarkosyl-extraction of tau fibrils from brain samples}

Frozen brain tissue was homogenized with a handheld TissueRuptor ${ }^{\circ}$ (Qiagen) in 10x v/w ice-cold buffer containing $10 \mathrm{mM}$ Tris- $\mathrm{HCl} \mathrm{pH} 7.5,0.8 \mathrm{M} \mathrm{NaCl}$ and $10 \%$ sucrose, supplemented with protease and phosphatase inhibitors (cOmplete ${ }^{\mathrm{Tm}}$ and PhosSTOP ${ }^{\mathrm{m}}$, Roche). Homogenates were centrifuged at 16,000 x $g$ at $4{ }^{\circ} \mathrm{C}$ for $20 \mathrm{~min}$, supernatants were collected and the pellets re-homogenized in $5 \mathrm{x} v / \mathrm{w}$ of ice-cold buffer and centrifuged again under the same conditions.
The two supernatants were combined and adjusted to $1 \%$ N-lauroylsarcosinate (sarkosyl) (w/v) (Sigma) and then agitated at room temperature for $1 \mathrm{~h}$. Each sample was then ultracentrifuged at $100,000 \times g$ at $4{ }^{\circ} \mathrm{C}$ for $1 \mathrm{~h}$. Resulting sarkosyl-insoluble pellets were resuspended in ice-cold PBS $(0.6 \mathrm{~mL}$ per $\mathrm{g}$ of starting material) and stored at $4{ }^{\circ} \mathrm{C}$ until use.

\section{Immunogold staining of brain sarkosyl-insoluble fraction tau}

Sarkosyl-insoluble fraction samples containing the tau fibrils were placed onto the center of a formvar/carboncoated 400 mesh nickel grid for $2 \mathrm{~min}$. The grids were then incubated for $5 \mathrm{~min}$ on a $25 \mu \mathrm{L}$ drop of blocking buffer: $1 \%$ horse serum, $1 \%$ BSA, $0.1 \%$ Tween-20 and $0.1 \%$ sodium azide in PBS. For pronase-treated samples, prior to the initial blocking, grids were incubated on a drop of $0.4 \mathrm{mg} / \mathrm{mL}$ of pronase (Sigma-Aldrich), for 4 min, followed by a brief wash in blocking buffer. Blocking was followed by incubation on a $25 \mu \mathrm{L}$ drop of primary antibody, diluted in blocking buffer, overnight at 4 ${ }^{\circ} \mathrm{C}$. The control Tau-5 antibody [64] (Thermo Sciences) used for double-labelling is a pan-tau antibody recognising amino acids 218-225 within the mid-domain of 2N4R tau. Following primary antibody incubation, grids were washed on a series of 3 drops of blocking buffer for $10 \mathrm{~min}$ on each drop. Grids were then incubated for $1.5 \mathrm{~h}$ on a $25 \mu \mathrm{L}$ drop of secondary antibody conjugated to either $6 \mathrm{~nm}$ or $12 \mathrm{~nm}$ colloidal gold particles diluted in PBS. Following incubation, the grids were washed on 2 drops of PBS for $30 \mathrm{~s}$ each, followed by a $5 \mathrm{~min}$ incubation on $2 \%$ glutaraldehyde in PBS to cross-link antibodies to other proteins. Fixation was followed by two $30 \mathrm{~s}$ washes in PBS and finally each sample was negatively stained by incubation on a drop of $2 \%$ phosphotungstic acid in $20 \mathrm{mM}$ phosphate buffer for $30 \mathrm{~s}$ exactly. Samples were left to dry and then viewed under a Jeol 1010 transmission electron microscope with Digital Image Capture.

\section{LC/MS analysis of tau peptides in human tauopathy brain} Frozen brain tissue from $\mathrm{AD}$ cases $(n=3$; Braak stage VI, frontal cortex), progressive supranuclear palsy cases $(n=4$; PSP, temporal cortex) and control brains $(n=2$; frontal cortex) were crushed in liquid nitrogen, weighed and then homogenised in 10 volumes of PBS containing HALT protease and phosphatase inhibitors (Thermo Fisher Scientific) with 20 strokes in a Dounce homogeniser on ice. Samples were centrifuged at $5250 \mathrm{x} g$ for 30 min at $4{ }^{\circ} \mathrm{C}$. Half the supernatant was retained. The remaining supernatant and pellet were re-homogenised and centrifuged as before. The two supernatants were pooled to create the clarified 'whole homogenate' for each sample. To obtain the insoluble fraction, whole homogenate samples were ultracentrifuged at 100,000 x 
$g$ at $4{ }^{\circ} \mathrm{C}$ for $1 \mathrm{~h}$. The insoluble pellet was resuspended in $0.2 \mathrm{~mL}$ of lysis buffer: $7 \mathrm{M}$ Urea, $2 \mathrm{M}$ thio-urea, $3 \%$ CHAPS, $1.5 \%$ n-octyl glucoside, $100 \mathrm{mM}$ triethyl ammonium bicarbonate (TEAB) and $50 \mathrm{mM}$ DTT. The suspension was sonicated and then, with protection from light, alkylated with $0.1 \mathrm{~mL}$ of $500 \mathrm{mM}$ iodoacetamide for $30 \mathrm{~min}$ at room temperature. For protein digestion, the Filter-Aided Sample Preparation (FASP) method [80] was employed with minor modifications. Briefly, protein solutions were loaded onto a Nanosep $10 \mathrm{~K}$ filter unit (PALL) and centrifuged at $8000 \times \mathrm{g}$ for $30 \mathrm{~min}$ at room temperature. Filter units were washed in $8 \mathrm{M}$ urea diluted in $100 \mathrm{mM}$ TEAB four times. Proteins were then dissolved in $5 \mathrm{M}$ urea/100 $\mathrm{mM}$ TEAB and then digested in the filter unit with $0.5 \mu \mathrm{g}$ Lys-C (Wako) at $37^{\circ} \mathrm{C}$ for $1 \mathrm{~h}$. Samples were then diluted to $1 \mathrm{M}$ urea in $100 \mathrm{mM}$ TEAB and then digested again with $0.5 \mu \mathrm{g}$ of sequencing-grade trypsin (Promega) at $37^{\circ} \mathrm{C}$ overnight. Digested samples were collected from the filter by centrifugation and then acidified to approximately $1 \%$ trifluoroacetic acid (TFA) and then desalted on a C18 solid phase extraction cartridge (GL Sciences). Peptides were eluted from the column with $80 \%$ acetonitrile/1\% TFA and then dried in a SpeedVac concentrator (ThermoScientific).

Tryptic peptides were analysed in a nano-flow LC-MS/ MS system using a Q Exactive HF mass spectrometer coupled with an online UltiMate 3000 Rapid Separation LC (Thermo Fisher Scientific) and an HTC PAL sample injector (CTC Analytics). Each sample was processed in data-dependent analysis (DDA) mode and all mass spectra were analysed with Proteome Discoverer v2.2 (ThermoFisher Scientific) using a human Swiss-Prot database incorporated with tau-441 sequence. This was followed by the label-free quantification of the identified peptides in each sample. To account for the variation in general tau abundance between individuals, the normalised abundance (\%) of each peptide within an individual sample was calculated by dividing the amount of measured peptide by the sum of all tau peptides in the same sample multiplied by 100 . The standardised abundance for each peptide was then used to allow comparison between samples. This was calculated using the following formula: $(X-\mu) / \sigma$ where $X$ is the normalised abundance of a peptide within a given sample, $\mu$ is the mean of normalised peptide abundance across all samples and $\sigma$ is the standard deviation of normalised peptide abundance across all samples. Changes in standardised abundance valued as the number of standard deviations above or below the mean could then be compared between AD, PSP and control cases.

\section{Size exclusion chromatography}

Aliquots of human brain 'whole homogenate' samples as described above were centrifuged at 21,000 x $g$ for 30 min at $4{ }^{\circ} \mathrm{C}$. The supernatant was retained and used as input material for chromatography. Briefly, $250 \mu \mathrm{L}$ of sample was loaded onto a Superdex 200 Increase G/L column connected to an Akta FPLC system (GE Healthcare). The chromatography buffer was PBS and $1 \mathrm{~mL}$ fractions were collected over 1.5 column volumes. Prior to use, the columns were calibrated with protein standards using the Gel Filtration HMW calibration kit (GE healthcare). To detect tau proteins, $75 \mu \mathrm{L}$ of each fraction was removed and mixed with $25 \mu \mathrm{L} 4 \mathrm{x}$ LDS sample buffer (Invitrogen) containing 10\% beta-mercaptoethanol. Proteins were then resolved on $4-12 \%$ Bis-Tris Novex gels (Invitrogen) and transferred to Hybond nitrocellulose membranes (GE healthcare). Blots were blocked for $1 \mathrm{~h}$ at room temperature in blocking buffer: a 1:1 mixture of Odyssey blocking buffer (LI-COR) and Tris-buffered saline containing $0.1 \%$ Tween-20 (TBS-T). After blocking, blots were probed with primary antibodies: either 7G6 $(0.5 \mu \mathrm{g} / \mathrm{mL}$ ) or HT7 (Thermo Scientific, $0.2 \mu \mathrm{g} / \mathrm{mL}$ ) diluted in blocking buffer. Blots were washed three times in TBS-T (10 min each wash) before incubation with an IRDye 700RD goat anti-mouse secondary antibody (LICOR) diluted at 1:5000 in blocking buffer for $1 \mathrm{~h}$ at room temperature. The secondary antibody was removed and blots were washed four times in TBS-T and then a further two times in TBS without Tween-20. Blots were then scanned and fluorescent images acquired using an Odyssey LiCor CLx scanner with the Image Studio software (LI-COR).

\section{Results}

\section{Generation and humanisation of antibodies}

For generating antibodies, two peptide immunogens were designed to span sequences within R2 and R3 of the MTBR in 4R-tau that include the sequences essential for pathological seeding and aggregation (Fig. 1) [11, 77, 78]. Peptide 1 (19 amino-acids) was designed to exclusively target 4R-tau isoforms and incorporated 17 residues from R2, including the PHF6* ${ }_{275}$ VQIINK $\left._{280}\right)$ motif and two residues from the adjoining R1. Peptide 2 (19 aminoacids) spanned the R2-R3 junction with the adjoined ${ }_{299} \mathrm{HVPGGGS}_{305}$ and PHF6 ( ${ }_{306} \mathrm{VQIVYK}_{311}$ ) sequences that together form metastable compact structures that modulate aggregation propensity [11]. An additional Nterminal cysteine was added to Peptide 2 for proteincoupling purposes. Peptides were conjugated to KLH to immunise Mapt-null mice in order to generate hybridomas. After ELISA screening and single-cell cloning, four antibody-producing hybridomas against Peptide 1 and eight against Peptide 2 were considered of interest for further study.

The affinities of the 12 antibodies for wild-type 2N4Rtau protein were initially measured by surface plasmon resonance $(\mathrm{SPR})$ and the $\mathrm{K}_{\mathrm{D}}$ values are given in Additional file 1: Table S1. We also initially determined 
selectivity of the antibodies to 3R- and 4R-tau by dot blot (Additional file 1: Table S1 and Additional file 1: Fig. S1A). Based on its exceptionally high affinity for wild-type recombinant tau expressed in E.coli $\left(\mathrm{K}_{\mathrm{D}}=52\right.$ pM), we selected clone 7G6, raised against Peptide 2 for further characterisation and subsequent humanisation. The dot blot showing the ability of 7G6 to bind decreasing amounts of $4 \mathrm{R}$ - or 3R-tau isoforms is shown in Additional file 1: Figure S1A.

The 7G6 antibody was humanised by grafting the complementarity-determining regions (CDRs) onto a human IgG1 backbone with IGHV3 and IGKV1 frameworks (Additional file 1: Figure S2). These frameworks, commonly represented in humans, have been used previously in FDA-approved therapeutic antibodies and are thought to present a lower risk of clinical immunogenicity. Also, a cysteine residue in CDR2 of the heavy chain, predicted to be solvent exposed and thus increasing the likelihood of post-translational modification (especially oxidation), was substituted to a serine residue. This substitution did not affect tau binding as assessed by ELISA (data not shown). The final humanised version of the 7G6 antibody was designated E2814.

To confirm that antibody characteristics and efficacy were maintained during the humanisation process, both 7G6 and E2814 antibodies were biotinylated and captured onto streptavidin-coated SPR chips. Full-length human wild-type $2 \mathrm{~N} 4 \mathrm{R}$ tau was then used as the analyte to determine antibody affinity. Table 1 shows that high affinity was retained during the humanisation process: 7G6 and E2814 had respective affinities of $64 \mathrm{pM}$ and $88 \mathrm{pM}$. The slightly lower affinity of E2814 was a consequence of a slightly faster off-rate compared to the 7G6 antibody.

Noting the comparable affinity of $7 \mathrm{G6}$ for both 3Rand 4R-tau, we assessed this with the humanised E2814 using SPR. Using a concentration range $(5,10,20,40$ and $80 \mathrm{nM}$ ) of cell-free expressed recombinant $2 \mathrm{~N} 4 \mathrm{R}$ and $2 \mathrm{~N} 3 \mathrm{R}$ tau as analytes, we showed dose-dependent binding of E2814 to both isoforms. E2814 retained strong affinity for $2 \mathrm{~N} 3 \mathrm{R}$ tau despite having one less binding site with the affinity being 0.37 -fold lower when compared to 2N4R-tau (Additional file 1: Figure S1B).

\section{Characterisation of 7G6 and E2814: Epitope-mapping with tau peptide microarray}

To identify the precise tau sequence recognised by 7G6 and E2814 antibodies, fine epitope mapping was carried

Table 1 Affinity determination of 7G6 and E2814 antibodies to wild type tau protein

\begin{tabular}{llll}
\hline Antibody & $k_{a}(1 / \mathrm{Ms})$ & $k_{d}(1 / s)$ & $K_{D}(M)$ \\
\hline $7 G 6$ (mouse) & $3.11 \times 10^{6}$ & $1.95 \times 10^{-4}$ & $6.36 \times 10^{-11}$ \\
E2814 (human) & $3.50 \times 10^{6}$ & $3.07 \times 10^{-4}$ & $8.81 \times 10^{-11}$ \\
\hline
\end{tabular}

out using PEPperCHIP ${ }^{\circ}$ customised peptide microarrays consisting of overlapping peptide sequences covering the entire 2N4R-tau protein (PEPperPRINT GmbH, Heidelberg, Germany). Both 7G6 and E2814 bound equally to HVPGG motifs found in the second- (R2; amino-acids 299-303) and fourth (R4; amino acids 362-366) repeat in 2N4R-tau (Fig. 2). Hence, both antibodies are bi-epitopic for 4R-tau. However, as R2 is absent in 3R-tau, only one of the HVPGG binding epitopes is present. This helps explain the lower affinity of E2814 for 3R-tau as described above. Two lower intensity signals indicated trace binding to HQPGG at amino acid positions 268 to 272 in R1; and HKPGG at positions 330 to 334 in R3 of 2N4R-tau.

Human MAPT gene mutations resulting in substitution of the proline at positon $301\left(\mathrm{P}_{301}\right)$ of $2 \mathrm{~N} 4 \mathrm{R}$-tau with a serine or leucine, is a cause of the tau-variant form of familial frontotemporal dementia. Since the P301S/L mutations cause a greater propensity for tau to aggregate, this mutation is often used pre-clinically to enhance tau aggregation both in vitro and in transgenic mouse models of tauopathy. Noting that this residue resides in the HVPGG motif in R2, we tested whether the mutation would impair binding of 7G6 to the mutated protein. SPR analysis (Table 2) demonstrated that, although 7G6 retains high, sub-nanomolar binding affinity (448 pM) to 2N4R-tau with the P301S mutation, this was lower compared to wild-type 2N4R-tau ( $36.9 \mathrm{pM})$.

To aid in interpretation of pre-clinical experiments utilising cellular and in vivo models expressing P301L/S mutant tau and to further investigate the binding requirements of 7G6, substitution analysis was performed using the peptide ${ }_{1} \mathrm{KDNIKHVPGGGSVQI}_{15}$ by systematically replacing each amino acid in the sequence with all 19 other amino acids (Additional file 1: Figure S3). Residues $\mathrm{H}_{6}, \mathrm{P}_{8}$ and $\mathrm{G}_{9}\left(\mathrm{H}_{299}, \mathrm{P}_{301}\right.$ and $\mathrm{G}_{302}$ in the fulllength protein), were found to have no tolerance for substitution by any amino acid. These data would also imply that $\mathrm{H}_{362}, \mathrm{P}_{364}$ and $\mathrm{G}_{365}$ are essential at the second HVPGG binding motif in the fourth repeat (R4). Importantly, substitutions corresponding to the P301S or P301L mutations completely abolished binding in support of our observation that, like 3R-tau, 7G6 binding to the full-length recombinant P301S mutant protein was due to recognition of just the intact HVPGG epitope within the R4 domain. Minimal tolerance for substitution was observed at the $G_{10}$ residue whereas a moderate tolerance at $V_{7}$ was detected. Residues flanking the HVPGG core motif also exert minor influence of 7G6 binding to the peptides.

\section{Western Blot and Immunohistochemical validation}

The specificity of 7G6 and E2814 antibodies were demonstrated by western blotting (Additional file 1: Figure S4). Tau proteins were detected in sarkosyl-insoluble 


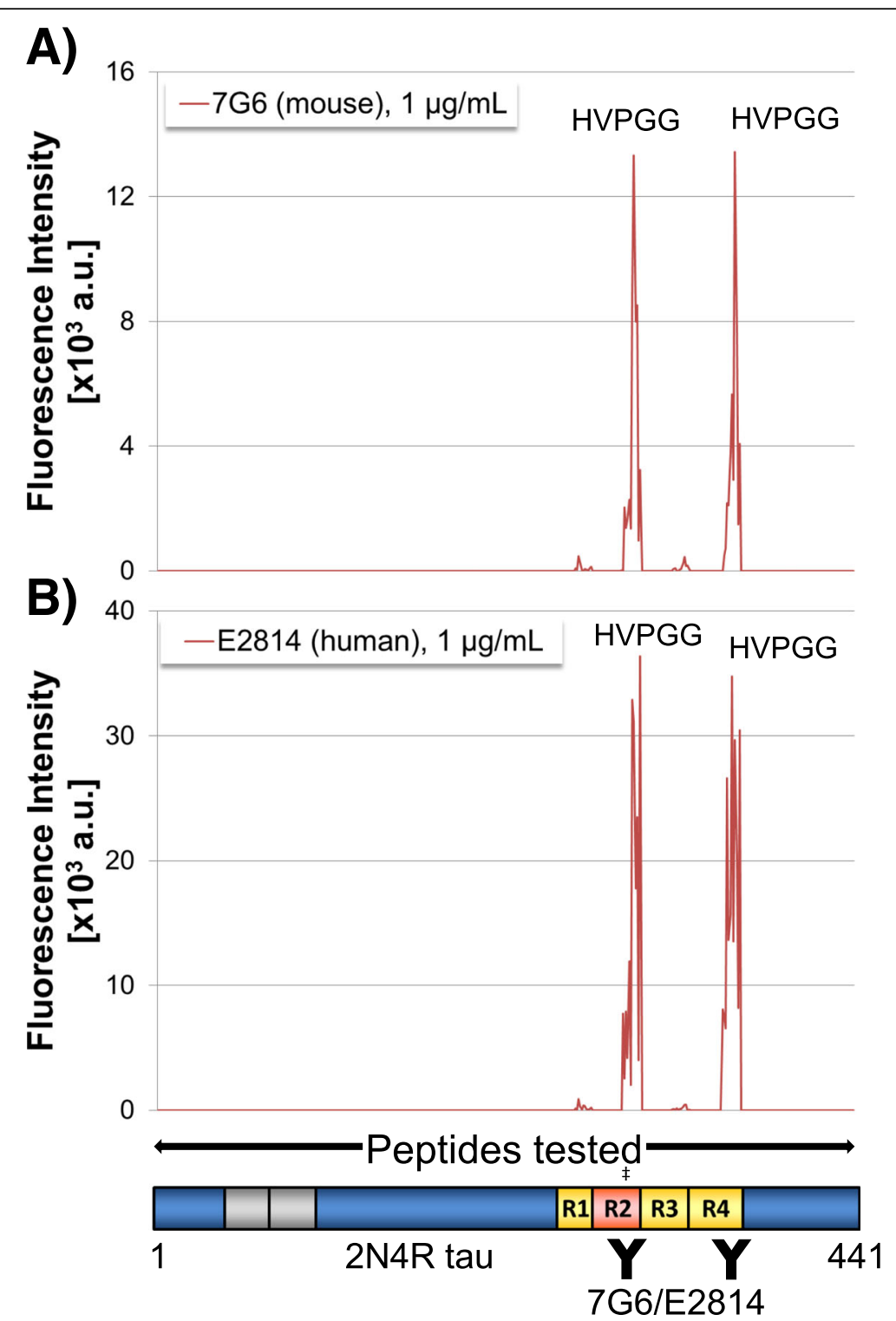

Fig. 2 Fine epitope mapping of 7G6 and E2814 anti-tau antibodies. Overlapping peptides covering the full length wild type human 2N4R tau sequence were synthesised and printed onto glass chips. Each chip was then probed with either a) 7G6 (mouse) or b) E2814 (human) antibodies at $1 \mu \mathrm{g} / \mathrm{mL}$. Bound antibodies were detected by the addition of fluorescently-labelled secondary antibodies and images captured using a LI-COR Odyssey machine. Fluorescent spots corresponding to antibody-bound peptides were quantified and intensity plots spanning the full tau sequence were generated for both murine 7G6 (a) and human E2814 (b) antibodies. Both antibodies bound peptides containing an HVPGG sequence as indicated in each panel

and -soluble brain fractions from rTg4510 transgenic mice [67] that overexpress human mutant P301L 0N4R tau, sarkosyl-soluble brain fractions from wild type mice but immunoreactivity was completely absent in total

Table 2 Affinity determination of 7G6 antibody to wild type and P301S mutant tau protein

\begin{tabular}{llll}
\hline Antigen & $k_{a}(1 / \mathrm{Ms})$ & $k_{d}(1 / s)$ & $K_{D}(M)$ \\
\hline Wild type tau & $1.65 \times 10^{6}$ & $6.10 \times 10^{-5}$ & $3.69 \times 10^{-11}$ \\
P301S tau & $6.82 \times 10^{5}$ & $3.06 \times 10^{-4}$ & $4.48 \times 10^{-10}$ \\
\hline
\end{tabular}

lysate from Mapt-null mice (Additional file 1: Figure S4A). Immunoreactivity to different isoforms of tau could not be assessed in these mouse samples since only 4R-tau is expressed in adult mouse brains [55].

To further confirm binding and isoform selectivity, we immunoprecipitated tau from Alzheimer's disease (AD) and Pick's disease (PiD) brain lysates with E2814 and with $\operatorname{IgG}_{1}$ as an isotype control. By western blotting with a pan-tau antibody (Dako, K9JA) of the precipitated (and dephosphorylated) proteins, and the unbound protein in the flow through, we show effective capture of both 3R- 
tau and 4R-tau by E2814 (Additional file 1: Figure S4B). E2814 immunoprecipitated protein showed relatively equal ratios of 3R-tau and 4R-tau and, also, near complete depletion in the unbound fraction.

We then sought to determine whether E2814 and 7G6 could recognise pathological tau features in fixed, human brain sections. The antibodies were tested on sections obtained from AD, progressive supranuclear palsy (PSP) and $\mathrm{PiD}$ patients to ascertain if they recognise the pathological tau inclusions characterising these cases. In addition to the hallmark extracellular $\beta$-amyloid plaques, the $A D$ brain is characterised by intraneuronal neurofibrillary tangles (NFTs) and neuropil threads, with the occasional astrocytic plaques consisting of insoluble aggregates of both 3R- and 4R-tau isoforms. In PSP brain, the more globose NFTs consist almost exclusively of 4R-tau [16] and, as with all 4R-tauopathies, also harbour 4R-tau glial inclusions in the form of tufted astrocytes (TAs) and oligodendroglial coiled bodies (CBs). Conversely, Pick bodies (PBs) in PiD contain only 3R-tau $[16,17,23]$.

We first optimised staining with different dilutions of the $7 \mathrm{G} 6$ and E2814 antibodies $(1 / 2000(0.5 \mu \mathrm{g} / \mathrm{mL}), 1 /$ $3000(0.33 \mu \mathrm{g} / \mathrm{mL})$ and $1 / 5000(0.2 \mu \mathrm{g} / \mathrm{mL}))$ in order to specifically label the pathological inclusions, where tau protein is enriched, over the basal cytoplasmic tau levels.
With all three clinical cases, both 7G6 and E2814 robustly stained all the cognate pathological tau inclusions (Fig. 3 (E2814) and Additional file 1: Figure S5 (7G6)) including NFTs and neuropil threads in AD (Fig. $3 \mathrm{a}-\mathrm{c}$ ) and NFTs as well as the TAs and CBs in PSP (Fig. $3 \mathrm{f}-\mathrm{k}$ ). Robust staining of the PBs in the PiD hippocampal granule cells (Fig. $3 \mathrm{~m}$ and $\mathrm{n}$ ), confirms strong binding despite the presence of only one of the two HVPGG binding motifs in 3R-tau-dominant PiD pathology [16, 17, 23]. Although E2814 can clearly bind the end-stage fibrillar tau structures in post mortem disease brain, it should be noted that the antibody does not selectively bind to defined pathological conformers of tau or phospho-tau proteins. This is demonstrated by Additional file 1: Figure S6 where, in areas adjacent to those with tau pathology, E2814 labels non-fibrillar tau in neuronal cytoplasm as well as neuropil, when compared to the human $\operatorname{IgG}_{1}$ control.

\section{Immunogold electron microscopy labelling of pathological tau fibrils}

To further characterise E2814 and 7G6 antibodies and to confirm that the HVPGG epitope was retained and accessible in pathological tau fibrils, antibody binding was determined by immunogold labelling. Tau fibrils and other structures in the sarkosyl-insoluble fraction of

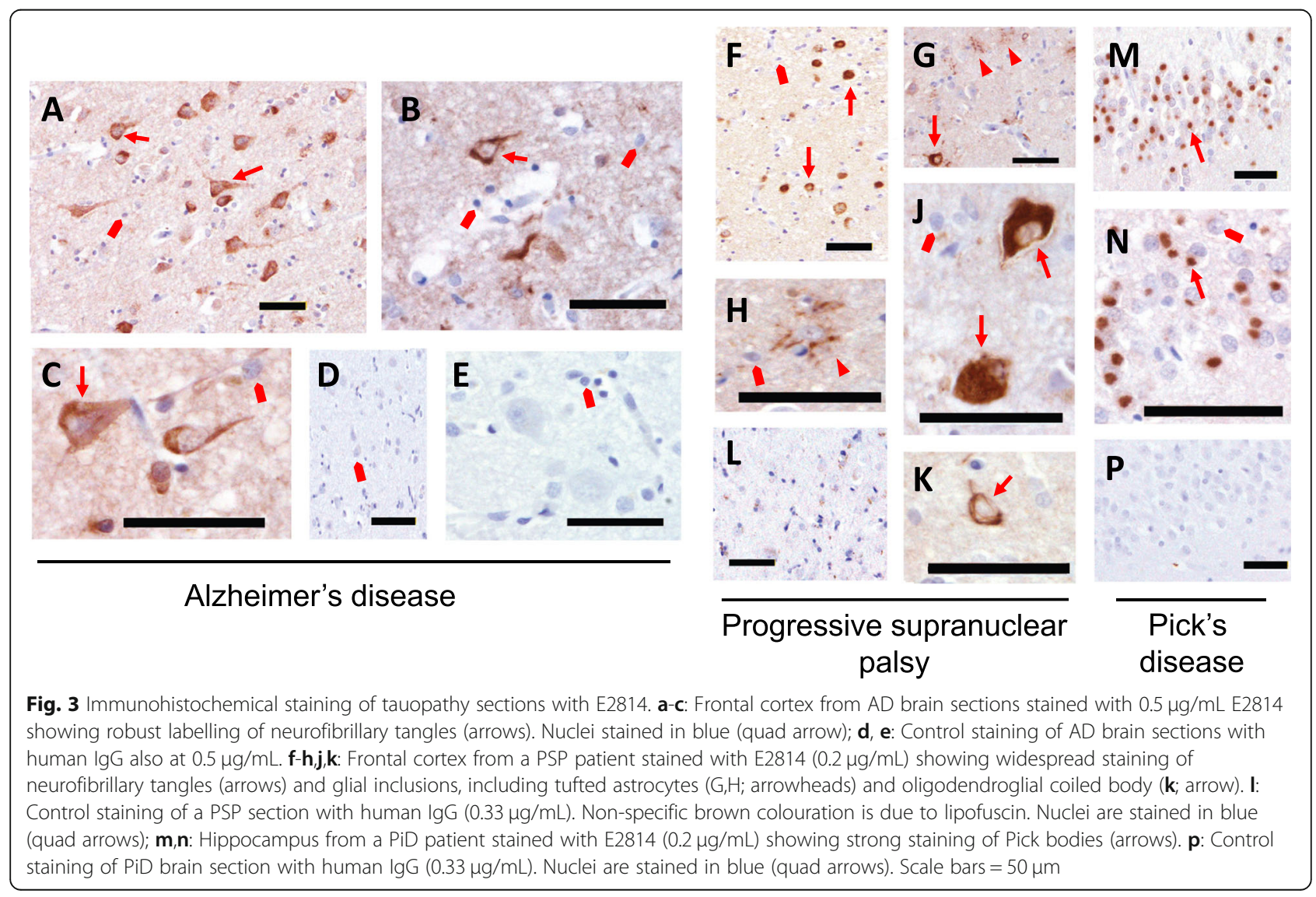


brain from an AD patient (Braak VI) were labelled with E2814 or a human $\operatorname{IgG}_{1}$ control antibody as described under Additional file 1: Supplementary Materials and
Methods. We used a series of antibody dilutions (10$0.05 \mu \mathrm{g} / \mathrm{mL}$ ) to determine optimal labelling. Saturation of possible binding sites at these optimal concentrations

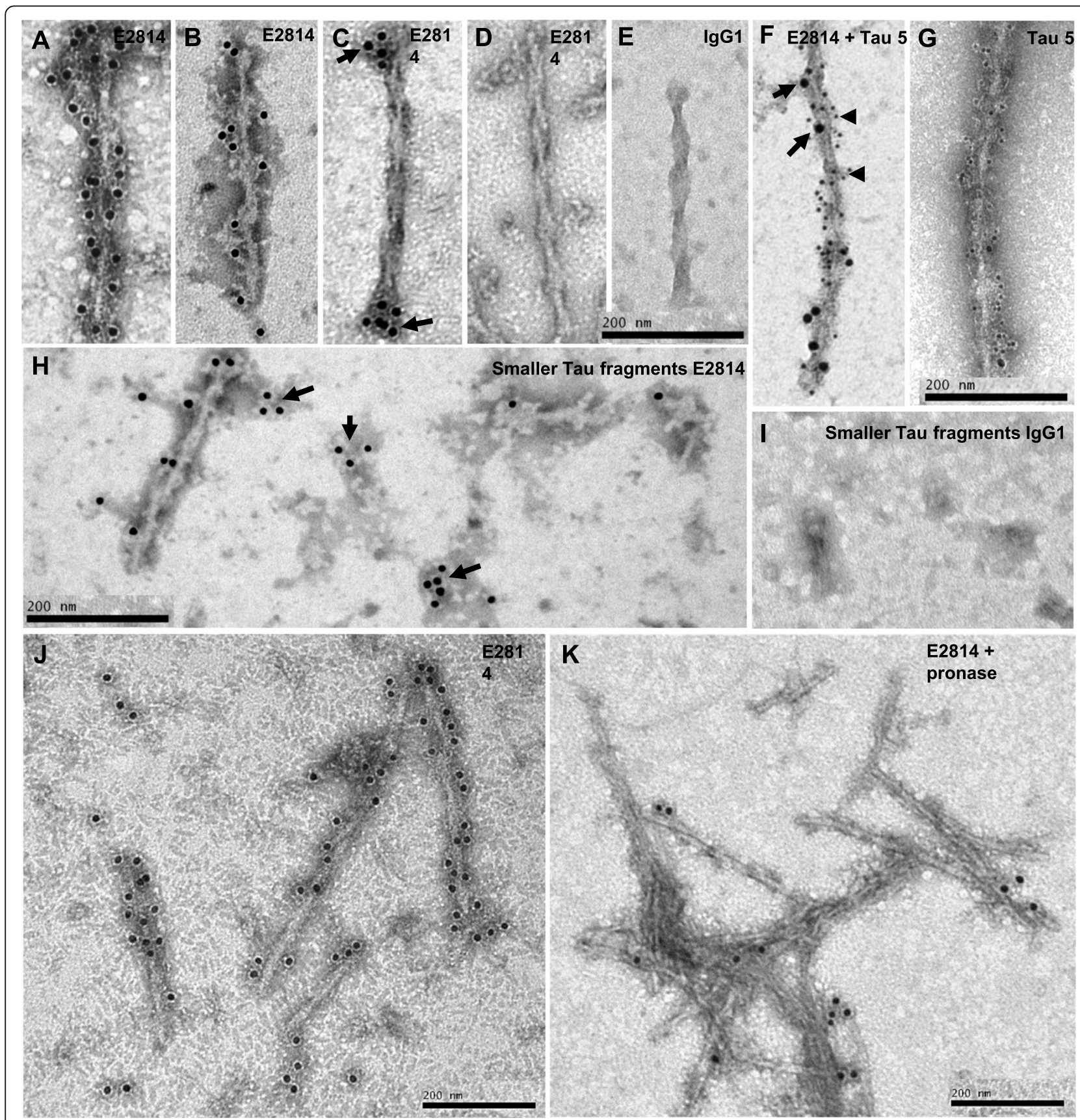

Fig. $4 \mathrm{Immunogold}$ labelling of tau filaments from human AD brain. Representative electron microscope images of tau fibrils isolated from the sarkosyl-insoluble fraction of AD patient frontal cortex. E2814 or lgG1 isotype control were used at $10 \mu \mathrm{g} / \mathrm{mL}$. Tau 5 antibody was used at $0.4 \mu \mathrm{g} /$ $\mathrm{mL}$. Bound antibody was detected following addition of an anti-human $12 \mathrm{~nm}$ gold conjugated antibody at 1:25 dilution or an anti-mouse $6 \mathrm{~nm}$ gold conjugated antibody at 1:25 dilution (for Tau 5). a, b: E2814 could bind the entire length of many tau fibrils. In some paired helical filaments (PHFs) E2814 binding was limited to the ends (arrows) of the fibrils (c) or was completely absent (d). f: E2814 (arrows) and the commercially available Tau 5 antibody (arrowheads) co-stain tau fibrils, providing proof of E2814 specificity to tau fibrils. g: Tau 5 binds to the entire length of tau fibrils. h: E2814 specifically binds to smaller structures on the EM grids that may represent tau fibril fragments or tau oligomers (arrows). The IgG1 control antibody did not bind to filbrils (e), or smaller fragments (f). j,k). Pre-treatment of AD fibrils with $0.4 \mathrm{mg} / \mathrm{ml}$ pronase removed the fuzzy coat of PHFs and SFs, leaving the structured core intact with E2814 staining retained only at some fibril ends (Scale bars $=200 \mathrm{~nm}$ ) 
were determined by incubation with a very high concentration of antibody $(100 \mu \mathrm{g} / \mathrm{mL})$ which showed similar labelling patterns and densities compared to $10 \mu \mathrm{g} / \mathrm{mL}$ (Additional file 1: Figure S8 F+G). Furthermore, specificity of binding was demonstrated by double labelling of the AD tau fibrils with E2814 and Tau-5 antibody (Fig. 4 f) and complete absence of immunogold labelling with the IgG control antibody (Fig. $4 \mathrm{e}+\mathrm{i}$ ).

The E2814 antibody binds to the entire length of many filaments. In some PHFs however, the binding was restricted to their ends or sometimes absent (Fig. $4 \mathrm{a}$-d). E2814 was also able to recognise smaller tau fragments that could either be due to shearing during the tissue processing or immature fibrils and perhaps even oligomers (Fig. $4 \mathrm{~h}$ ), the latter suggested to be the transmissible pathological tau species in human disease [30]. The same binding pattern was also observed with the murine 7G6 antibody (Additional file 1: Figure S7). Treatment of the fibrils with pronase to remove the fuzzy coat abolished E2814 binding along the length of the fibrils (Fig. $4 \mathrm{~J}$ and $\mathrm{K}$ ), suggesting that E2814 binds mainly to the R2 epitope that resides in the the fuzzy coat around the AD tau fibril [26]. Only endbinding of fibrils remained after pronase treatment, suggesting that the R4 epitope may be exposed at fibril ends.

In addition to AD fibrils, E2814 robustly decorated tau fibrils isolated from the frontal cortex of a frontotemporal dementia (FTLD-tau) patient with the MAPT missense mutation R406W (Additional file 1: Figure S8A), and another patient carrying the MAPT $\triangle 280 \mathrm{~K}$ deletion (Additional file 1: Figure S8B). Occasional labelling was observed on tau fibrils isolated from the frontal cortex of a FTLD-tau patient with the IVS10 + 16 mutation that leads to increased incorporation of the exon 10 (Additional file 1: Figure S8C). In PSP, E2814 did not bind along the length of isolated fibrils but was seen on some smaller structures (Additional file 1: Figure S8D). In fibrils isolated from the frontal cortex of a Pick's disease patient, binding was only observed at the filament ends (Additional file 1: Figure S8E). These data illustrate that the structures of mature tau fibrils differ between the tauopathies as well as between mutation carriers.

In support of our observation that E2814 can bind to the HVPGG epitope in pathological tau fibrils isolated from tauopathy brains, we also demonstrated binding to tau aggregates in solution. By immunoprecipitation, we showed that E2814 effectively binds to and depletes seed-competent K18 fibrils (truncated tau; amino acids 244-372) (Fig. $6 \mathrm{a}$ and b) and 7G6 recognises preformed recombinant 2N4R P301S tau fibrils (Additional file 1: Figure S11).

\section{Inhibition of tau aggregation and seeding}

Next, we evaluated the biological functionality of 7G6 and E2814 antibodies. Recombinant 2N4R tau protein was aggregated in vitro by co-incubation with heparin over several days and aggregates were revealed and quantified by Thioflavin $\mathrm{S}$ (ThS) binding. Heparininduced aggregation was carried out with incubation of approximately equimolar amounts of wild-type or $2 \mathrm{~N} 4 \mathrm{R}$ P301S mutant recombinant tau in the absence (buffer alone) or presence of either 7G6, E2814, or control IgG. Both 7G6 and E2814 showed a strong and significant inhibitory effect on tau aggregation (Fig. 5), suggesting that, if aggregation-competent tau is accessible to and
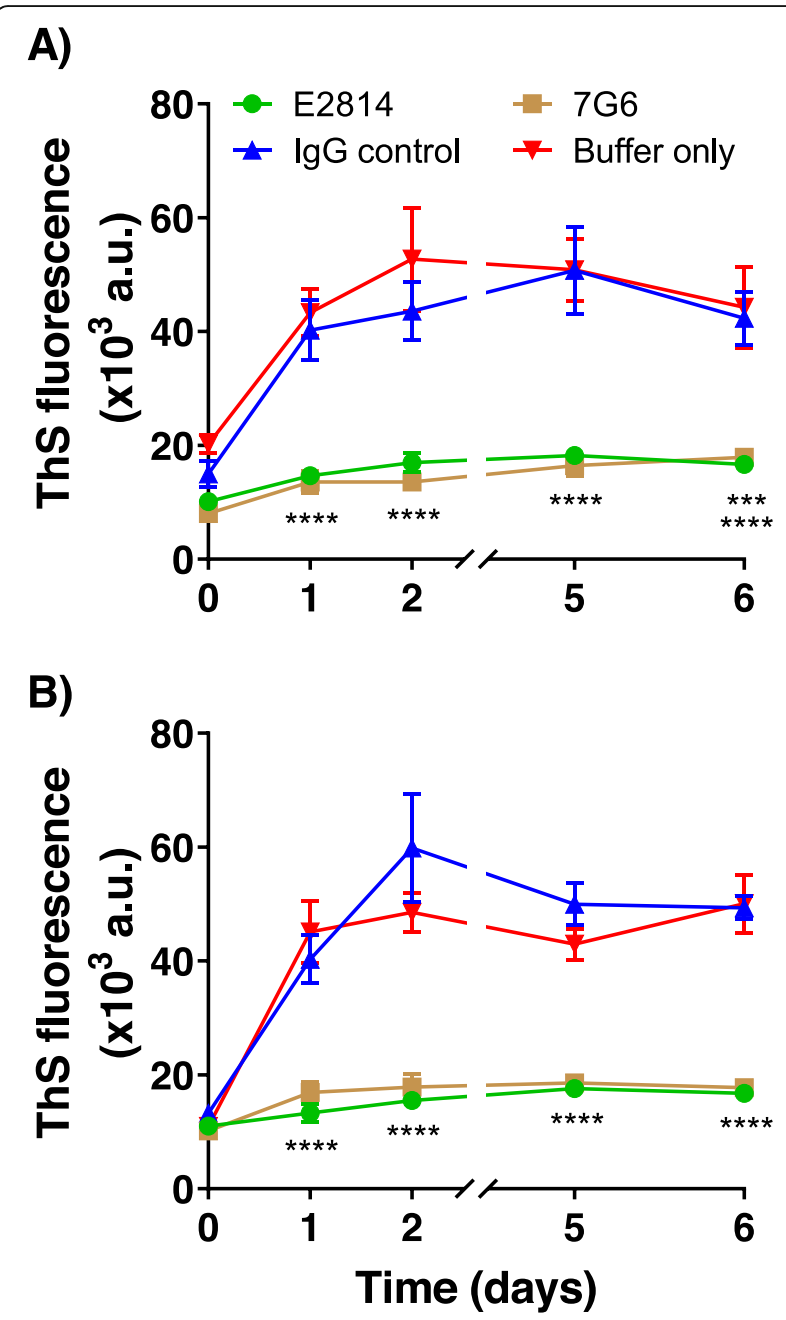

Fig. 5 Inhibition of tau aggregation in vitro. Recombinant wild-type (a) or P301S mutant (b) tau at $12 \mu \mathrm{M}$ was induced to aggregate in vitro with addition of heparin in the absence or presence of either 7G6, E2814 or control $\lg G_{1}$ antibodies at a concentration of $8.3 \mu \mathrm{M}$. Over a time course of 6 days, samples of the reaction mixture were removed and incubated with Thioflavin S (ThS) and fluorescence was measured to detect aggregated tau. Data shown represent six independent experiments for each protein. A two-way ANOVA statistical analysis was performed followed by a Dunnett's test. ${ }^{* * *} p \leq 0.00017 \mathrm{G} 6$ or E2814 versus lgG, ${ }^{* * *} p \leq 0.0017 \mathrm{G} 6$ vs $\mathrm{lgG}$ for wild type protein only. Values represent mean \pm SEM 
bound by E2814, the antibody may have the ability to prevent further tau aggregation in a disease setting.

It has been reported that the MTBR region of tau is necessary to form seeds that propagate tau pathology in humans [22]. To verify these findings, a cell-based assay of tau deposition was established. Fibrillar or monomeric tau proteins were added to HEK293 cells overexpressing 0N4R P301S tau, and after $48 \mathrm{~h}$ intracellular tau deposition was detected by staining the cells with Thioflavin S. Recombinant tau proteins containing the MTBR but not those without the MTBR were able to induce intracellular tau deposition (Additional file 1: Figure S9), thus confirming previous reports. The most effective MTBRcontaining tau seeds tested in this assay were K18 fibrils (truncated tau; amino acids 244-372) and the full-length 2N4R P301S monomer. Next, to determine whether E2814 had the ability to recognise such seeds in their native form, the antibody or an IgG control was used to immunodeplete both K18 tau fibrils and 2N4R P301S tau monomer prior to cell addition. Intracellular tau deposition was reduced for both types of seed in a dosedependent manner when depleted with the E2814 antibody compared to IgG control (Fig. 6). These data raise the possibility that pathological MTBR-containing tau seeds in human brain could be sequestered and masked by E2814.

To determine whether E2814 could potentially prevent transmission of pathological tau in the brain, the murine antibody 7G6 was tested in a pre-clinical in vivo model of tau transmission. The model requires full-length 2N4R P301S tau seeds to be injected into the hippocampus of 3 to 4 month old 0N4R P301S transgenic mice [3] backcrossed onto a C57/BL6 genetic background. At this age, the mice show no overt tau pathology in the brain as assessed by immunostaining for pathological tau species (data not shown). After 3 weeks, brain tissue from the ipsilateral and contralateral sides to injection were extracted and the levels of sarkosyl-insoluble tau quantified by western blot. To test antibody efficacy, 7G6 or an IgG control antibody was dosed peripherally (i.p.) at $40 \mathrm{mg} / \mathrm{kg}$

\section{A)}

C)
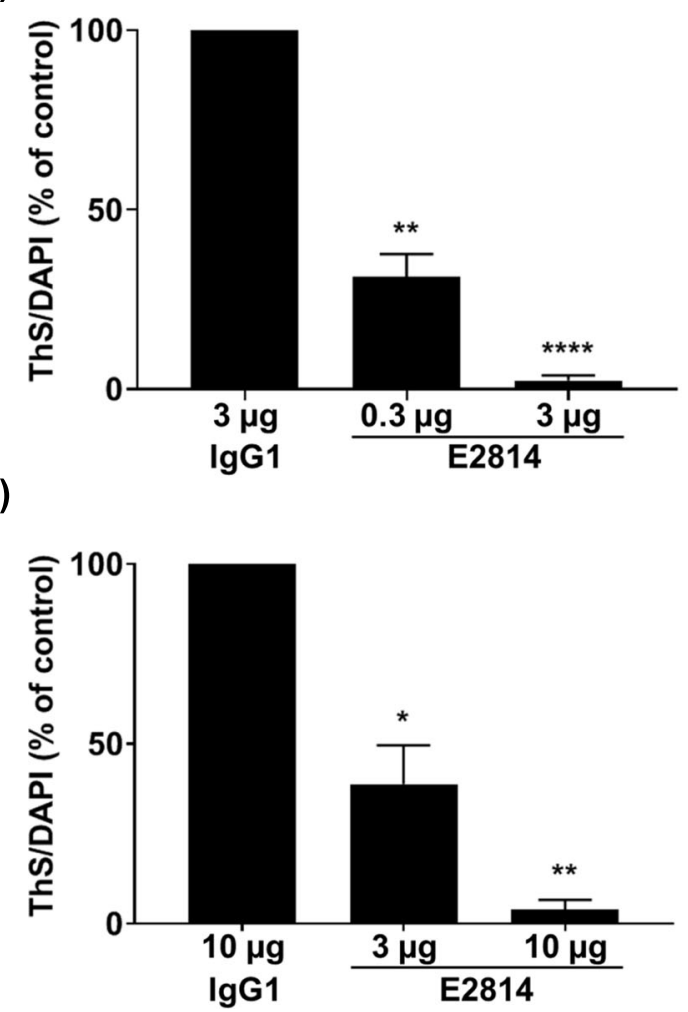

B)

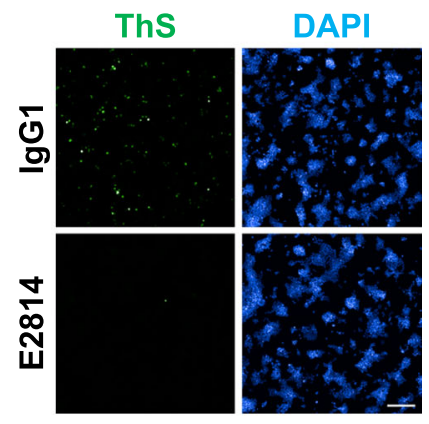

D)

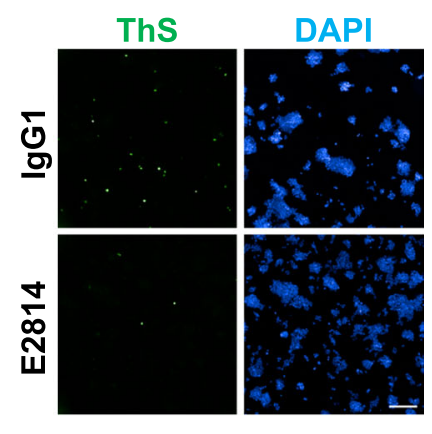

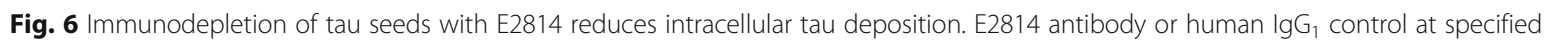
concentrations were used to immunodeplete K18 fibrils $(\mathbf{a}, \mathbf{b})$ or full length P301S tau monomer (c,d) seeds. Treated samples were added to HEK293 cells overexpressing P301S mutant 0N4R tau. Intracellular tau deposition was measured by addition of Thioflavin S (ThS) and cells were counterstained with DAPI to visualise the nuclei. The percentage of ThS/DAPI relative to $\operatorname{lgG}_{1} \mathrm{control}$ is $\mathrm{plotted}\left(\mathrm{lg} \mathrm{G}_{1}=100 \%\right.$ seeding effect). Values represent the mean \pm SEM from four (a) and three $(\mathbf{c})$ independent experiments. Data were analysed by one way ANOVA followed by Dunnett's test. ${ }^{*} P<0.05,{ }^{*} P<0.005,{ }^{* * *}<0.0001$. Representative images of ThS and DAPI staining for K18 fibril (B, $3 \mu \mathrm{g}$ antibody) and P301S monomer (d, $10 \mu \mathrm{g}$ antibody) immunodepleted seeds are shown. Scale bars $=200 \mu \mathrm{m}$ 
prior to seed administration and then once per week for a following 3 weeks. A group of animals that were dosed with vehicle but did not receive tau seed were included as controls. Following peripheral 7G6 treatment, a modest, yet significant reduction in sarkosyl-insoluble tau levels was observed in the contralateral hippocampus compared to the IgG control group (Fig. 7 b; Additional file 1: Figure S10). However, a significant effect in the corresponding ipsilateral tissue was not observed (Fig. 7 a; Additional file 1: Figure S10). The data suggest that 7G6 (and E2814) are capable of attenuating the transmission of pathological tau species in this in vivo model. To show that the 7G6 antibody had successfully crossed the blood-brain barrier, albeit in expected low amounts, antibody levels were measured in both plasma and CSF of treated animals (Additional file 1: Table S2). The mean plasma/CSF concentration ratio was $0.08 \%$ in this experiment.

\section{AD brain tau peptide mapping}

It is well documented that tau protein from human brain is proteolytically cleaved at numerous positions along its length $[38,51,79]$ and suggested that this truncation may play an important role in AD pathology [62]. Many of the resulting tau fragments contain the MTBR but it is not possible to state currently, whether in human brain, full-length tau seeds or MTBR-containing fragments are responsible for propagation of pathology. To gain a deeper understanding of whether the regions of tau containing the E2814 epitopes alter in disease, a mass spectrometry technique was employed to compare relative levels of tau tryptic peptides spanning the whole tau protein in the insoluble fractions from different tauopathy and control brains. Following relative quantification, several tryptic peptides across the protein showed significant changes between AD, PSP and control samples. Most notably, peptides 299-317, 322-340, 354-369 and 354-370 were enriched in AD samples compared to PSP or control (Fig. 8). These peptides, containing both E2814 epitopes, in the tau MTBR are within the Cterminal half of R2 to the end of R4. Conversely, other peptides showing significant change between $A D$ and PSP were either contained N-terminal to $299-317$ or Cterminal to 354-370. The data demonstrate that in the insoluble fraction of AD brain compared to PSP or control, although using low numbers of samples, an accumulation of the tau MTBR containing both E2814 epitopes is evident. This raises the possibility that the Cterminal half of the tau MTBR may be more important in $\mathrm{AD}$ pathogenesis compared to other tauopathies.

To investigate further the fragments of tau in tauopathy brain recognised by the $7 \mathrm{G6}$ antibody, human brain homogenates were analysed by size exclusion chromatography. Brain homogenate was loaded onto the column and fractions were then collected from the first eleven fractions after the column void volume. Each fraction was analysed by western blotting using 7G6 or the anti-tau antibody HT7 which recognises the middomain of tau at amino acids 159-163 (Fig. 9). When analysing all $\mathrm{AD}$ samples, tau fragments resolving as a

\section{A) Ipsilateral}

\section{B) Contralateral}
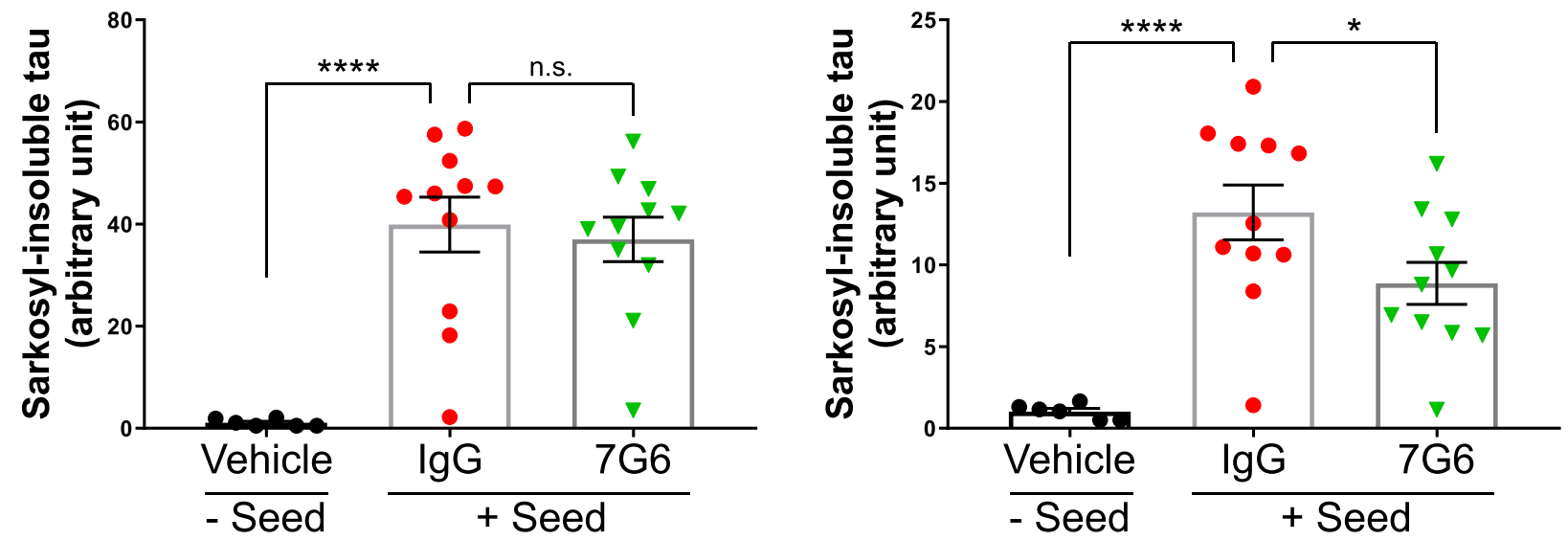

Fig. 7 G6 efficacy in an in vivo model of tau seeding and transmission. Full-length P301S tau seeds were injected into the left hippocampus of P301S transgenic mice pretreated with either lgG control $(n=11)$ or $7 \mathrm{G} 6$ antibody $(n=11)$ at a dose of $40 \mathrm{mg} / \mathrm{kg}$ i.p. Animals then received the same dose of antibody or vehicle once per week for a further 3 weeks until sacrifice. Vehicle-treated animals receiving no seed $(n=6)$ were included as an additional control group. Both hippocampi from each brain were extracted and separately treated with sarkosyl. Tau levels were then quantified in the sarkosyl-insoluble fraction from each sample by western blot and plotted for either the ipsilateral (a) or contralateral (b) hippocampi for each animal. Data are expressed as mean \pm SEM and further analysed using a one-way ANOVA followed by Fisher's LSD test. **** $p \leq 0.0001 \mathrm{lgG}$ versus no seed control, * $p \leq 0.057 \mathrm{G} 6$ versus lgG for contralateral hippocampus, n.s. not significant 


\section{Standardised Abundance}

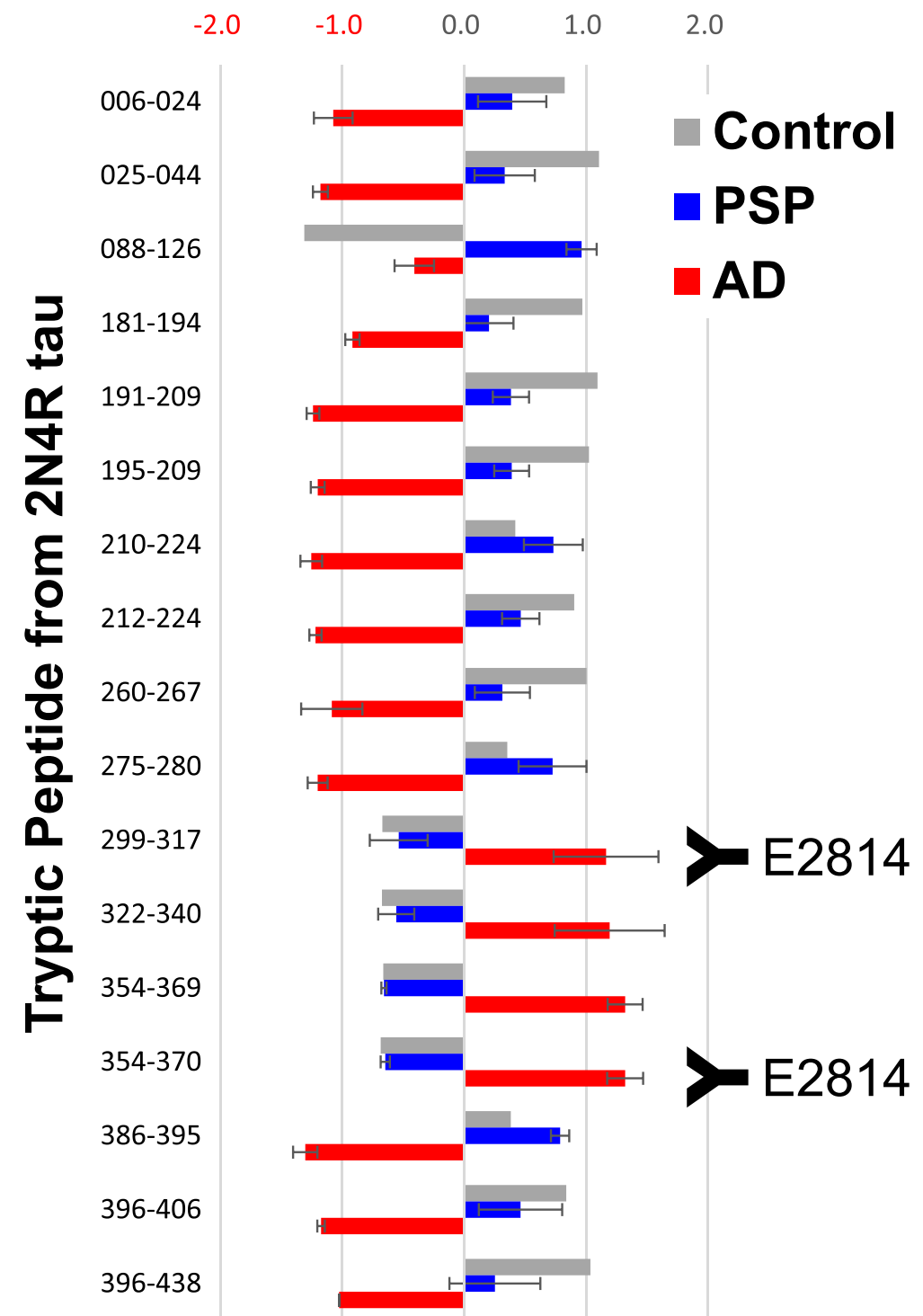

Fig. $8 \mathrm{LC} / \mathrm{MS}$ analysis of tau peptide abundance in the insoluble fraction from human tauopathy brain. Insoluble fractions from $\mathrm{AD}(n=3)$, PSP $(n=4)$ and control $(n=2)$ brain samples were prepared and digested with Lys-c and trypsin. Tryptic peptides were identified and quantified by LC/MS. The standardised abundance for each tau peptide was calculated (see Materials and Methods) and compared between AD, PSP and control brain samples. Peptides showing significant change between PSP and AD are plotted. Error bars for AD and PSP represent

standard deviation

smear were only detectable in the high molecular weight fractions when revealed by MTBR-recognising 7G6 antibody but not with the mid-domain HT7 antibody. Similar data have been reported previously using other antibodies [58]. These observations suggest that multiple truncated tau species containing the MTBR are found in the higher molecular weight fractions and the majority of these tau species do not contain the mid-domain, HT7-binding portion of the protein. The tau smears in the higher molecular weight fractions detectable with the 7G6 antibody were only apparent in samples from $\mathrm{AD}$ brain and neither PSP brain (Fig. 9) nor control brain (data not shown). Both antibodies detected abundant bands in fractions 4 to 7 , most likely to be fully intact tau isoforms. However, further, discrete truncation of tau was clearly visible in the lower molecular weight fractions 8 to 11 with more truncated tau species containing either the whole or part of the MTBR identified on the basis of 


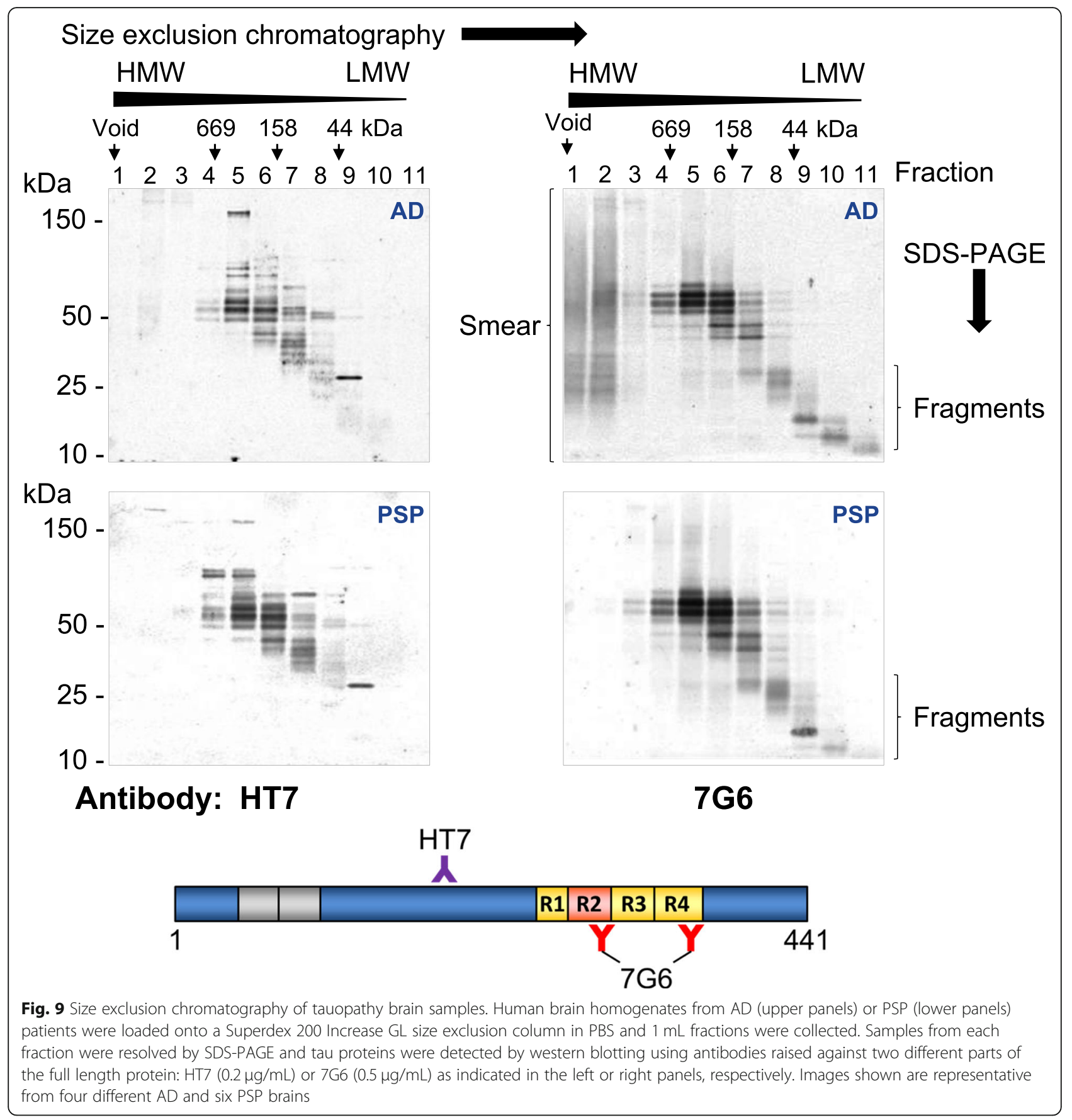

strong immunoreactivity being observed with 7G6 but not HT7. A distinctive, discrete tight band in fraction 9 was clearly detected with HT7 but not the 7G6 antibody, suggesting this to be a tau fragment lacking the 7G6 epitopes within the MTBR. The low molecular weight tau species were detectable in all homogenates tested but the biological function, if any, of such fragments requires further investigation. If accessible, it is anticipated that E2814 binding to a variety of MTBR-containing tau species could prove therapeutically beneficial by either direct neutralisation or enhancing their clearance.

\section{Discussion}

Therapeutic agents targeting tau proteins have emerged as a new strategy to alter disease progression in a number of tauopathies, including Alzheimer's disease (AD). Increasing evidence suggests that tau pathology progressively spreads throughout the brain during disease 
course and contributes to the neuronal cell compromise and death ultimately responsible for onset and progression of symptoms. Early reports of tau pathology in AD Braak staging [8] described initial deposition in the entorhinal cortex followed by propagation to the limbic regions and beyond, giving strong credence to the notion that tau pathology spreads along connected neuronal pathways. It is also suggested that the spread of pathology occurs through extracellular pathological tau "seeds" that are transmitted from neuron to neuron [1]. The precise molecular nature of the seeds are unknown but this mechanism may provide several opportunities for therapeutic intervention, including passive immunization with appropriate monoclonal antibodies.

Here, we describe E2814 as a unique, high-affinity, biepitopic humanised $\operatorname{IgG}_{1}$ antibody for possible therapeutic application in AD and other tauopathies. Our initial strategy was to raise antibody candidates recognising regions within the tau MTBR that incorporate key sequences essential for the formation of pathological seeds and initiation of aggregation [22]. E2814, and its murine counterpart 7G6, bind to sequence epitope HVPGG present twice in tau isoforms with four microtubulebinding repeats (4R-tau; HVPGG is present within R2 and R4) and once in three-repeat (3R-tau) isoforms (R4 only). By binding to HVPGG, both antibodies effectively inhibit 4R-tau aggregation in vitro. In immunohistochemical staining of human brain tissue, the antibodies recognised mature pathological tau structures such as neurofibrillary tangles in $\mathrm{AD}$ and progressive supranuclear palsy (PSP) as well as Pick bodies in Pick's disease (PiD), the latter a tauopathy whose inclusions contain only 3Rtau isoforms. This confirms the presence of the MTBR, containing the HVPGG in the inclusions. However, pathological phosphorylation- or conformation-specific antibodies such as AT8 [32] or MC1 [46], respectively, E2814 is not selective for pathological tau per se. Instead, by binding to the HVPGG epitope(s), E2814 could not only intervene in the misfolding of tau and formation of seeds but also facilitate their clearance.

Noting that the most widely used pre-clinical models of tauopathy employ cDNA-based transgenes overexpressing P301S or P301L variants whereby the mutation lies in the middle of the R2 HVPGG motif, it was of concern that weakened binding to tau with those mutations could limit experimental outcomes. Indeed, binding of $7 \mathrm{G} 6 \mathrm{com}$ pletely relied on the presence of the P301 residue since substitution by any other amino acid completely abolished binding (Additional file 1: Figure S3). However, even with just one HVPGG epitope in R4 remaining, 7G6 retained high-affinity binding $\left(\mathrm{K}_{\mathrm{D}}=448 \mathrm{pM}\right)$ to $2 \mathrm{~N} 4 \mathrm{R}$ P301S tau but this was less when compared to the wild-type protein (36.9 pM). Both 7G6 and E2814 were equally effective in preventing in vitro heparin-induced aggregation of recombinant wild-type- and P301S tau (Fig. 5) despite loss of one epitope in the mutant protein. Furthermore, immunodepletion of seed-competent K18 peptide (repeat region only of wild-type 4R-tau) or recombinant 0N4R P301S monomer with E2814, resulted in effective removal of seeding activity in cells overexpressing 0N4R P301S tau. These data suggest that high-affinity binding of E2814 to the second HVPGG motif in R4 is sufficient to prevent seeded pathological spread and aggregation by masking the necessary conformational interfaces. As with binding to 0N4R P301S tau, we have also demonstrated that 7G6 and E2814 effectively bind to 3R-tau isoforms and expect therefore that these antibodies will also prevent aggregation of 3R-tau.

The conversion of highly-soluble tau into its seedcompetent, aggregation prone form involves the short hydrophobic domains of the MTBR normally responsible for binding to microtubules [48]. New structural information has also emerged that has given further insight into the mechanism of pathological tau species formation to strengthen the rationale to further investigate E2814. For example, recent work has demonstrated that conformational conversion to seed competent tau is caused by unmasking the PHF6 motifs $\left({ }_{275} \mathrm{VQIINK}_{280} /{ }_{306} \mathrm{VQIVYK}_{311}\right)$, rendering them more accessible to illicit intermolecular seeding interactions and aggregation [57]. In soluble tau, these motifs are normally masked by adopting compact $\beta$ hairpin pairings with flanking sequences [57] that include the R2 HVPGG motif [11]. Furthermore, disease-causing missense mutations in the flanking $\mathrm{N}$ terminal region, including those in the R2 HVPGG sequence such as P301L/S [10, 12, 19, 43, 66, 73, 74], significantly increase the aggregation propensity of tau by destabilising the $\beta$-hairpin to cause a more extended conformation of the region exposing the PHF6 motifs [11]. This allows cross- $\beta$ sheet rearrangements and interactions resulting in highly compact and stable protofibril structures that self-assemble into the characteristic end-stage filaments. Protofibrils from different tauopathies also adopt unique characteristic folds $[23,24,26]$. In $A D$ protofilaments for example, the HVPGG binding motif in R4 is essential for formation of the inner bend and compaction of the $\mathrm{C}$-shaped protofibril but would be predicted as inaccessible to E2814 in structurally established protofibrils (Fig. 10). However, the HVPGG motif in R2 is not part of the compact protofilament, and is therefore predicted to be more accessible to both E2814 and 7G6 antibodies.

Considering these structural insights, we surmise that E2814 may exert an effect by binding to and stabilising the accessible HVPGG motifs in the $\beta$-hairpin pairings that mask the PHF6 motifs in soluble tau, thus preventing conformational conversion to seed-competent tau. 


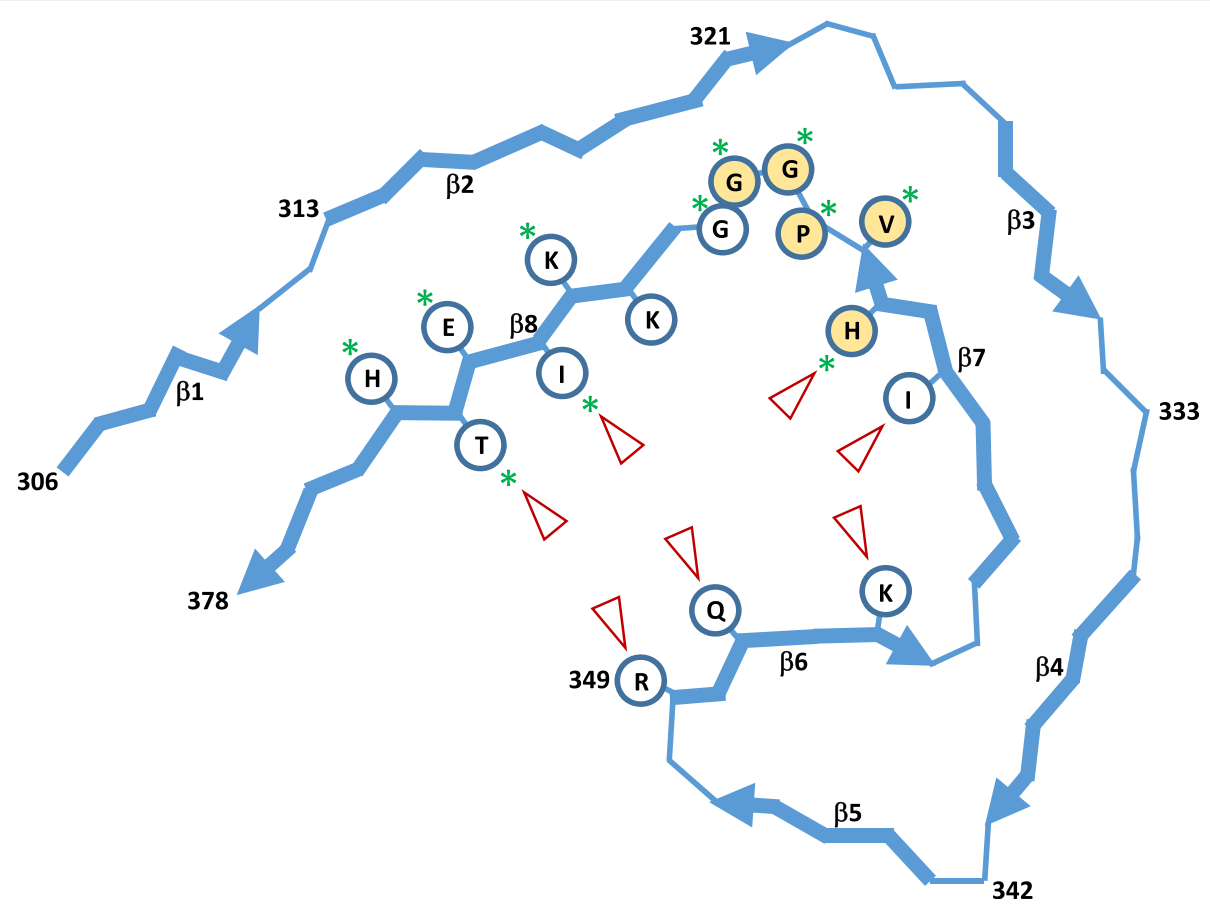

Fig. 10 AD tau protofibril structure (modified from [26]): Schematic representation of protein backbone of the R3 + R4 protofibril unit of AD tau paired-helical filaments and straight filaments, with selected amino acid side chains. The numbering of amino acid positions is based on the 2N4R-tau isoform (NP_005901). Antiparallel $\beta$-strands are indicated by thick arrows. In AD, the protofibril adopts a compact C-shaped structure. The E2814 HVPGG binding motif (362-366; yellow) forms the tight bend between $\beta_{7}$ and $\beta_{8}$. Red arrowheads indicate predicted strong contact points to heparin [53] resulting in heparin-mediated aggregation by compaction and stabilization of the AD protofibril. Green stars indicate sequences that interact with azure $A$ and azure $B$, monodemethylated derivatives of methylene blue (MB), which have anti-aggregation effects on tau by preventing fibril formation and retaining tau in monomeric form [2]

E2814 binding at either R2 or R4 sites could also sterically prevent the intermolecular seeding interactions. We have shown here that E2814 retains efficacy in preventing heparin-mediated aggregation of P301S indicating that intervention at the R4 HVPGG site is sufficient. Although the R4 HVPGG motif is predicted to be inaccessible in the structurally mature $\mathrm{AD}$ protofibril, it is possible that binding by E2814 at earlier stages of conformational conversion and misfolding could prevent formation and compaction of the protofibril and subsequent fibril assembly.

To further illustrate the importance of the E2814 binding sites, heparin, a glycosaminoglycan that co-exists with tau in neurons with neurofibrillary pathology [63], and small molecule aggregation inhibitors can be used as examples. Heparin facilitates the aggregation of tau by exposing the PHF6 hexapeptide motifs [21] and, in accordance with the $\mathrm{AD}$ protofibril structure, is predicted to interact with amino acid side chains lining the groove of the $\mathrm{C}$-shaped core to mediate folding and stabilisation. One of those amino acids is the $\mathrm{H}_{362}$ residue in the R4 HVPGG (362-366) motif (Fig. 10) [53]. Conversely, small molecule tau aggregation inhibitors, azure $\mathrm{A}$ and azure B, also interact with ${ }_{362} \mathrm{HVPGGG}_{367}$ as well as
${ }_{371} \mathrm{IETH}_{374}$ [2] contained within the R4 region. Given that E2814 could inhibit P301S tau aggregation in vitro it is plausible that binding to the R4 HVPGG is sufficient to sterically prevent formation and maturation of tau fibrils in AD brain.

Although the mechanism of tau seeding and propagation of pathology is poorly understood, it is now widely accepted that pathological tau variants (seeds) escape affected neurons and enter neighbouring, or synaptically-connected neurons [27]. It has been suggested that the transmissible seeds could either be high molecular weight assemblies [76], non-fibrillar oligomeric tau species [52] or, seed-competent conformations of monomeric tau [57]. In addition to inhibiting further aggregation, binding of MTBR-containing extracellular seed-competent tau species may lead to prevention of neuronal tau uptake [81]. Since E2814 is an $\mathrm{IgG}_{1}$ antibody with retained effector function, it is also possible that once bound to extracellular seed-competent tau species, microglial cells would be stimulated to accelerate clearance of the unwanted tau conformers in an antibody-dependent manner. Such clearance effects have previously been demonstrated in the clinic for human 
$\mathrm{IgG}_{1}$ antibodies targetting amyloid in $\mathrm{AD}$ patients [71]. Another potential clearance mechanism could be through the ubiquitously expressed cytosolic $\mathrm{F}_{\mathrm{c}}$ receptor, tripartite motif protein 21 (TRIM21), that has been reported to mediate the degradation of antibody-bound tau seeds entering the cell [54].

To test the effect of $7 \mathrm{G6}$ in vivo, we unilaterally injected fibrillar P301S mutant 2N4R-tau into the left hippocampus of P301S transgenic mice [3] and treated the animals systemically with 7G6 antibody or a mouse IgG control. After 3 weeks, we observed attenuated levels of sarkosyl-insoluble tau in the contralateral hippocampus in 7G6-treated mice compared with control-treated mice but no differences were demonstrated in the injected half of the brain (Fig. 7). Despite the limitations of these data, e.g. reliance on the P301S mutation which may underestimate antibody efficacy due to weakening of binding at the R2 site, they do support the notion that the 7G6 antibody reduces seeded propagation of tau aggregation in the brain by being able to target conformational intermediates. This supports our hypothesis, at least under the conditions of this model, that the humanised form of 7G6 (E2814) can target the tau species involved in transmission that lead to further tau seeding and aggregation.

A number of reports have also demonstrated that truncated tau species are important upstream contributors to pathological aggregation of tau $[4,28,36,37,42$, $59,65]$ and that they can also form the pathological seeds $[15,62,83]$. Interestingly, CSF tau from $\mathrm{AD}$ and PSP patients have higher levels of tau fragments from the amino-terminus and central region of the protein but are depleted of fragments containing the MTBR $[7,56]$. Perhaps, selective sequestration of MTBR fragments occurs in brain pathological inclusions. As an adjunct in the assessment of the potential therapeutic efficacy of E2814, we investigated the abundance of its target MTBR domains in insoluble, pathological tau fractions from AD and PSP brains as well as in brain homogenates. Mass spectrometric (MS) analysis of tryptic peptides from insoluble brain fractions revealed a particular enrichment of peptides from the MTBR domain in the samples studied from AD compared to PSP brain and control brain. By contrast, an accumulation of tau peptides from the amino- and carboxy-terminal as well as mid-domains of tau were apparent in samples of PSP brain and control brain compared with AD (Fig. 8). The more abundant MTBR domain peptides in AD span aminoacid residues 299-370 to include both E2814 binding motifs and the entire R3 and R4 domains that form the stable AD protofibril core. This specific overrepresenation, compared to PSP and controls, suggests that the stable core $\mathrm{AD}$ protofibril is protected from endogenous proteolytic cleavage whether physiological or associated with pathological aggregation. Nevertheless, in the samples analysed, there are clear differences in the accumulation of MTBR-containing tau species in AD brain compared to PSP or control.

Although the protofibril structures from 3R-/4Rtauopathies (AD and CTE) and a 3R-tauopathy (PiD) were resolved by cryo electron microscopy (Cryo-EM) $[23,25,26]$, it had previously been a challenge to isolate sufficient sarkosyl-insoluble fibrillar tau from 4Rtauopathies (e.g. PSP, CBD and argyrophilic grain disease). Recently however, the core CBD 4R-tau protofibril structure has now also been reported [82]. In our hands, normalised yields of insoluble tau from 4R-tauopathies are considerably lower (data not shown), suggesting less stable fibril structure with greater susceptibility to proteolytic degradation. This was evident when we compared size-fractionated tau from brain homogenates where we observed an absence of higher order 7G6-positive tau assemblies in PSP, compared to samples from AD (Fig. 9). Interestingly, the smear seen in the higher molecular weight fractions of AD brains (Fig. 9; Fractions 1 and 2) were labelled by $7 \mathrm{G6}$, but not by HT7, an antibody that recognises the mid-region of tau suggesting excessive tau proteolysis had occurred but the MTBR region was retained in higher order assemblies. These data accord with similar findings of tau analysis in sarkosyl-insoluble brain fractions reported elsewhere using alternative antibodies [58]. It is currently unclear whether the accumulation of cleaved tau containing the MTBR forms the intracellular fibril core in $\mathrm{AD}$, or is representative of the extracellular 'ghost tangles' that remain once the cell expires. Interestingly, we also see a consistent, discrete banding pattern between AD and PSP samples for the lower molecular weight tau fragments that are immunoreactive for either HT7 or 7 G6 (Fig. 9). This reiterates that tau truncation is perhaps not a random process, but rather by highly specific proteolytic cleavages and nonenzymatic fragmentation [83]. For example, the discrete band identified at around $25 \mathrm{kDa}$ (Fig. 9: Fraction 9) labelled only with HT7 suggests that it lacks the MTBR whereas smaller $(<25 \mathrm{kDa})$ fragments contain the MTBR.

Importantly, our combined immunohistochemistry, immunogold-EM, immunoprecipitation and western blot analyses demonstrate that E2814, and its murine parent antibody 7G6, recognise human brain tau (full-length or fragments) and thus could intervene in and prevent the crucial conformational folding of the MTBR that leads to the genesis of pathological seeding species. This would ultimately prevent the tight folding and maturation of the AD tau fibrils. 


\section{Conclusions}

We have described E2814, a humanised IgG 1 antibody for passive immunotherapy, targeting with high-specifity and affinity two motifs in the MTBR that form the core sequences required for pathological aggregation of tau. Given the unique binding characteristics, high binding affinity and functional pre-clinical activity of E2814, further clinical investigation is warranted to test whether the antibody can indeed prevent further aggregation of tau and slow transmission of pathology in $\mathrm{AD}$ and potentially other tauopathies.

\section{Supplementary information}

Supplementary information accompanies this paper at https://doi.org/10 1186/s40478-020-0884-2.

Additional file 1: Table S1. Affinity and approximate isoform selectivity of anti-tau monoclonal antibodies raised against Peptides 1 and 2. Figure S1. Assessment of antibody selectivity for 4R- and 3R-tau isoforms by dot blot and surface plasmon resonance (Biacore). Figure S2. E2814 antibody humanisation from mouse $7 \mathrm{G} 6$ - schematic representation of the strategy for E2814 generation. Figure S3. Substitution scanning of $7 \mathrm{G} 6$ antibody affinity requirements on the wild-type tau peptide ${ }_{1}$ KDNIKHVPGGGSVQI ${ }_{15}$. Figure S4. Selectivity of $7 G 6$ and E2814 antibodies. Figure S5. Immunohistochemical labelling by 7G6 of tau fibrillar inclusions in tauopathy brains. Figure S6. Immunohistochemical labelling of brain tau by E2814. Figure S7. Immunogold labelling of AD filaments with mouse 7G6 antibody. Figure S8. E2814 immunogold labelling of tau filaments from different tauopathies. Figure $\mathbf{S 9 .}$

Seeding capacity of different tau fragments. Figure S10. Western blots from the seed-injection study to assess the efficacy of 7G6 in vivo. Table S2. Pharmacokinetic data from the intrahippocampal seed injection study. Figure S11. Immunoprecipitation of recombinant aggregated P301S tau. Supplementary Materials and Methods.

\section{Abbreviations}

3R-tau: Tau isoforms with three microtubule-binding repeat domains; 4Rtau: Tau isoforms with four microtubule-binding repeat domains; AD: Alzheimer's disease; APP: Amyloid precursor protein; BSA: Bovine serum albumin; CB: Coiled body; CBD: Corticobasal degeneration; CDR: Complementarity determining region; ELISA: Enzyme-linked immunoassay; FBS: Foetal bovine serum; FTD: Frontotemporal dementia; i.p.: Intraperitoneal; MAPT: Microtubule-associated protein, tau; MT: Microtubule; MTBR: Microtubule-binding region; NFT: Neurofibrillilary tangle; PiD: Pick's disease; PIPES: Piperazine-N,N'-bis(2-ethanesulphonic acid); PSP: Progressive supranuclear palsy; R1,R2,R3,R4: First, second, third and fourth microtubule-binding repeat domain, respectively; RU: Response units; SPR: Surface plasmon resonance; TA: Tufted astrocyte; TRIM21: Tripartite motif protein 21

\section{Acknowledgements}

The authors are grateful to the patients and their families for generously donating brain tissues used in this project as without their support, the research would not have been possible. The Queen Square Brain Bank is supported by the Reta Lila Weston Institute, the Progressive Supranuclear Palsy Association and the Medical Research Council.

We thank the members of the Eisai:UCL Therapeutic Innovation Group (TIG): A. Takle, T. Warner, R. Ketteler, P. Atkinson, H. Plun-Favreau, A. Isaacs, A. Groom and L. Ravenhill for scientific discussion and guidance on this, the TIGC project. We also thank Y. Hashizume from Eisai's Tsukuba Research Laboratories who helped design in vitro and in vivo experiments and $Y-Y$ Chan, A. Milinichik and S. Jacob, all from Eisai Inc. Exton, for hybridoma scale up and purification of antibodies. We thank M. Turmaine at UCL Biosciences Electron Microscopy Facility for training and technical support.

\section{Authors' contributions}

Conceptualisation: MR, IS, YI, JG, HO, ZZ, SA, NT, MO,HA, ES, KH, JMS, RdS; Data Curation and formal analysis: MR, IS, YI, KM, ST, MD, HO, ZZ, MO, ES, KH, RdS; Funding acquisition: RdS; Investigation: MR, IS, YI, KM, ST, MD, HO, ZZ, SA, NT, MA, KS, ES, KA, JS, EA, KH, KH, RdS; Methodology: All; Project Administration: MR, JG, HO, MO, HA, JS, EA, KH, KH, JMS, RdS; Resources: MR, JMS, RdS; Supervision: MR, SA, MO, HA,JMS, RdS; Validation: MR, IS, YI, JG, HO, ZZ, SA, NT. MO, MA, HA, KS, ES, KLA, JS, EA, KH; Visualisation: MR, IS, YI, KM, ST, MD, HO, MA, KS, ES, KLA, KH, RdS; Writing original: MR, IS, YI, MO, KLA, JS, $E A, K H, J M S, R d S$; Writing: Review \& Edit: MR, IS, JMS, RdS. All authors read and approved the final manuscript.

\section{Availability of data and materials}

All data generated or analysed during this study are included in this published article [and its supplementary information files].

\section{Ethics approval and consent to participate}

Animals.

Animal care and experimental procedures were performed in an animal facility accredited by the Health Science Center for Accreditation of Laboratory Animal Care and Use of the Japan Health Sciences Foundation. All protocols were approved by the Institutional Animal Care and Use Committee and carried out in accordance with, as appropriate, the Animal Experimentation Regulations of Eisai Co., Ltd or Cell Engineering Corporation. Postmortem brain.

Post-mortem fixed and frozen brain samples were obtained from the Queen Square Brain Bank for Neurological Disorders, (UCL Queen Square Institute of Neurology, London). Ethical approval for the study was obtained from the Local Research Ethics Committee of the National Hospital for Neurology and Neurosurgery, London, UK. The tissue was stored for research purposes under license 12198 from the Human Tissue Authority, UK.

\section{Consent for publication}

Not applicable.

\section{Competing interests}

All work performed to generate data reported in this manuscript was funded by Eisai, a pharmaceutical company listed on the Tokyo Stock Exchange (TYO:4523). MR, YI, KM, ST, MD, JG, HO, ZZ, SA, NT, MO, MA, HA, KLA, JS, EA, $\mathrm{KH}$ and JMS were full-time employees of Eisai for the period in which data reported in this study were generated. IS and ES are UCL employees funded by Eisai through the Eisai:UCL Therapeutic Innovation Group (TIG). The TIG is a collaborative partnership between Eisai and UCL to discover and advance medical therapies for neurodegenerative disorders. Successful medical therapies from the collaboration could potentially be of commercial benefit to both Eisai and UCL. RdS and KS are UCL employees and also funded by the Reta Lila Weston Trust for Medical Research.

\section{Author details}

${ }^{1}$ Hatfield Research Laboratories, Eisai Limited, Hatfield, UK. ${ }^{2}$ Reta Lila Weston Institute \& Department of Clinical and Movement Neurosciences, UCL Queen Square Institute of Neurology, 1 Wakefield Street, London, UK. ${ }^{3}$ Tsukuba Research Laboratories, Eisai Co., Tsukuba-shi, Ibaraki, Japan. ${ }^{4}$ Eisai Inc., Welsh Pool Road, Exton, PA, USA.

Received: 5 December 2019 Accepted: 24 January 2020

Published online: 04 February 2020

\section{References}

1. Ahmed Z, Cooper J, Murray TK, Garn K, McNaughton E, Clarke H, Parhizkar S, Ward MA, Cavallini A, Jackson S et al (2014) A novel in vivo model of tau propagation with rapid and progressive neurofibrillary tangle pathology: the pattern of spread is determined by connectivity, not proximity. Acta Neuropathol 127:667-683. https://doi.org/10.1007/s00401-014-1254-6

2. Akoury E, Pickhardt M, Gajda M, Biernat J, Mandelkow E, Zweckstetter M (2013) Mechanistic basis of phenothiazine-driven inhibition of Tau aggregation. Angew Chem Int Ed Engl 52:3511-3515. https://doi.org/10 1002/anie.201208290

3. Allen B, Ingram E, Takao M, Smith MJ, Jakes R, Virdee K, Yoshida H, Holzer M, Craxton M, Emson PC et al (2002) Abundant tau filaments and 
nonapoptotic neurodegeneration in transgenic mice expressing human P301S tau protein. J Neurosci 22:9340-9351

4. Arai T, Ikeda $K$, Akiyama H, Nonaka T, Hasegawa M, Ishiguro K, Iritani S, Tsuchiya K, Iseki E, Yagishita S et al (2004) Identification of amino-terminally cleaved tau fragments that distinguish progressive supranuclear palsy from corticobasal degeneration. Ann Neurol 55:72-79. https:/doi.org/10.1002/ana.10793

5. Asuni AA, Boutajangout A, Quartermain D, Sigurdsson EM (2007) Immunotherapy targeting pathological tau conformers in a tangle mouse model reduces brain pathology with associated functional improvements. J Neurosci 27:9115-9129. https://doi.org/10.1523/JNEUROSCI.2361-07.2007

6. Barghorn S, Mandelkow E (2002) Toward a unified scheme for the aggregation of tau into Alzheimer paired helical filaments. Biochemistry 41: 14885-14896

7. Barthelemy NR, Gabelle A, Hirtz C, Fenaille F, Sergeant N, Schraen-Maschke S, Vialaret J, Buee L, Junot C, Becher F et al (2016) Differential Mass Spectrometry Profiles of Tau Protein in the Cerebrospinal Fluid of Patients with Alzheimer's Disease, Progressive Supranuclear Palsy, and Dementia with Lewy Bodies. J Alzheimers Dis 51:1033-1043. https://doi.org/10.3233/JAD-150962

8. Braak H, Braak E (1991) Neuropathological stageing of Alzheimer-related changes. Acta Neuropathol 82:239-259

9. Braak H, Braak E (1995) Staging of Alzheimer's disease-related neurofibrillary changes. Neurobiol Aging 16:271-278 discussion 278-284

10. Bugiani $O$, Murrell JR, Giaccone G, Hasegawa M, Ghigo G, Tabaton M, Morbin M, Primavera A, Carella F, Solaro C et al (1999) Frontotemporal dementia and corticobasal degeneration in a family with a P301S mutation in tau. J Neuropathol Exp Neurol 58:667-677. https://doi.org/10.1097/ 00005072-199906000-00011

11. Chen D, Drombosky KW, Hou Z, Sari L, Kashmer OM, Ryder BD, Perez VA, Woodard DR, Lin MM, Diamond Ml et al (2019) Tau local structure shields an amyloid-forming motif and controls aggregation propensity. Nat Commun 10:2493. https://doi.org/10.1038/s41467-019-10355-1

12. Clark LN, Poorkaj P, Wszolek Z, Geschwind DH, Nasreddine ZS, Miller B, Li D, Payami H, Awert F, Markopoulou K et al (1998) Pathogenic implications of mutations in the tau gene in pallido-ponto-nigral degeneration and related neurodegenerative disorders linked to chromosome 17. Proc Natl Acad Sci U S A 95:13103-13107. https://doi.org/10.1073/pnas.95.22.13103

13. Cleveland DW, Hwo SY, Kirschner MW (1977) Purification of tau, a microtubule-associated protein that induces assembly of microtubules from purified tubulin. J Mol Biol 116:207-225

14. Congdon EE, Sigurdsson EM (2018) Tau-targeting therapies for Alzheimer disease. Nat Rev Neurol 14:399-415. https://doi.org/10.1038/s41582-018-0013-z

15. de Calignon A, Fox LM, Pitstick R, Carlson GA, Bacskai BJ, Spires-Jones TL, Hyman BT (2010) Caspase activation precedes and leads to tangles. Nature 464:1201-1204. https://doi.org/10.1038/nature08890

16. de Silva R, Lashley T, Gibb G, Hanger D, Hope A, Reid A, Bandopadhyay R, Utton M, Strand C, Jowett T et al (2003) Pathological inclusion bodies in tauopathies contain distinct complements of tau with three or four microtubule-binding repeat domains as demonstrated by new specific monoclonal antibodies. Neuropathol Appl Neurobiol 29:288-302

17. Delacourte A, Sergeant N, Wattez A, Gauvreau D, Robitaille Y (1998) Vulnerable neuronal subsets in Alzheimer's and Pick's disease are distinguished by their tau isoform distribution and phosphorylation. Ann Neurol 43:193-204. https://doi.org/10.1002/ana.410430209

18. D'Souza I, Schellenberg GD (2005) Regulation of tau isoform expression and dementia. Biochim Biophys Acta 1739:104-115. https://doi.org/10.1016/j. bbadis.2004.08.009

19. Dumanchin C, Camuzat A, Campion D, Verpillat $P$, Hannequin D, Dubois B, Saugier-Veber P, Martin C, Penet C, Charbonnier F et al (1998) Segregation of a missense mutation in the microtubule-associated protein tau gene with familial frontotemporal dementia and parkinsonism. Hum Mol Genet 7: 1825-1829. https://doi.org/10.1093/hmg/7.11.1825

20. Duyckaerts C, Clavaguera F, Potier MC (2019) The prion-like propagation hypothesis in Alzheimer's and Parkinson's disease. Curr Opin Neurol 32:266271. https://doi.org/10.1097/WCO.0000000000000672

21. Eschmann NA, Georgieva ER, Ganguly P, Borbat PP, Rappaport MD, Akdogan Y, Freed JH, Shea JE, Han S (2017) Signature of an aggregation-prone conformation of tau. Sci Rep 7:44739. https://doi.org/10.1038/srep44739

22. Falcon B, Cavallini A, Angers $R$, Glover S, Murray TK, Barnham L, Jackson S, O'Neill MJ, Isaacs AM, Hutton ML et al (2015) Conformation determines the seeding potencies of native and recombinant Tau aggregates. J Biol Chem 290:1049-1065. https://doi.org/10.1074/jbc. M114.589309
23. Falcon B, Zhang W, Murzin AG, Murshudov G, Garringer HJ, Vidal R, Crowther RA, Ghetti B, Scheres SHW, Goedert M (2018) Structures of filaments from Pick's disease reveal a novel tau protein fold. Nature 561: 137-140. https://doi.org/10.1038/s41586-018-0454-y

24. Falcon B, Zhang W, Schweighauser M, Murzin AG, Vidal R, Garringer HJ, Ghetti B, Scheres SHW, Goedert M (2018) Tau filaments from multiple cases of sporadic and inherited Alzheimer's disease adopt a common fold. Acta Neuropathol 136:699-708. https://doi.org/10.1007/s00401-018-1914-z

25. Falcon B, Zivanov J, Zhang W, Murzin AG, Garringer HJ, Vidal R, Crowther RA, Newell KL, Ghetti B, Goedert M et al (2019) Novel tau filament fold in chronic traumatic encephalopathy encloses hydrophobic molecules. Nature 568:420-423. https://doi.org/10.1038/s41586-019-1026-5

26. Fitzpatrick AWP, Falcon B, He S, Murzin AG, Murshudov G, Garringer HJ, Crowther RA, Ghetti B, Goedert M, Scheres SHW (2017) Cryo-EM structures of tau filaments from Alzheimer's disease. Nature 547:185-190. https:/doi.org/10.1038/nature23002

27. Funk KE, Mirbaha H, Jiang H, Holtzman DM, Diamond MI (2015) Distinct Therapeutic Mechanisms of Tau Antibodies: Promoting Microglial Clearance Versus Blocking Neuronal Uptake. J Biol Chem 290:21652-21662. https://doi. org/10.1074/jbc. M115.657924

28. Gamblin TC, Chen F, Zambrano A, Abraha A, Lagalwar S, Guillozet AL, Lu M, Fu Y, Garcia-Sierra F, LaPointe N et al (2003) Caspase cleavage of tau: linking amyloid and neurofibrillary tangles in Alzheimer's disease. Proc Natl Acad Sci U S A 100:10032-10037. https://doi.org/10.1073/pnas.1630428100

29. Gerson JE, Mudher A, Kayed R (2016) Potential mechanisms and implications for the formation of tau oligomeric strains. Crit Rev Biochem Mol Biol 51:482-496. https://doi.org/10.1080/10409238.2016.1226251

30. Ghag G, Bhatt N, Cantu DV, Guerrero-Munoz MJ, Ellsworth A, Sengupta U, Kayed $R$ (2018) Soluble tau aggregates, not large fibrils, are the toxic species that display seeding and cross-seeding behavior. Protein Sci 27:1901-1909. https://doi.org/10.1002/pro.3499

31. Goedert M (2016) The ordered assembly of tau is the gain-of-toxic function that causes human tauopathies. Alzheimers Dement 12:1040-1050. https:// doi.org/10.1016/j.jalz.2016.09.001

32. Goedert M, Jakes R, Vanmechelen E (1995) Monoclonal antibody AT8 recognises tau protein phosphorylated at both serine 202 and threonine 205. Neurosci Lett 189:167-169. https://doi.org/10.1016/0304-3940(95)11484-e

33. Goedert M, Spillantini MG, Cairns NJ, Crowther RA (1992) Tau proteins of Alzheimer paired helical filaments: abnormal phosphorylation of all six brain isoforms. Neuron 8:159-168. https://doi.org/10.1016/0896-6273(92)90117-v

34. Goedert M, Spillantini MG, Jakes R, Rutherford D, Crowther RA (1989) Multiple isoforms of human microtubule-associated protein tau: sequences and localization in neurofibrillary tangles of Alzheimer's disease. Neuron 3:519-526

35. Greenberg SG, Davies P (1990) A preparation of Alzheimer paired helical filaments that displays distinct tau proteins by polyacrylamide gel electrophoresis. Proc Natl Acad Sci U S A 87:5827-5831. https://doi.org/10. 1073/pnas.87.15.5827

36. Guillozet-Bongaarts AL, Glajch KE, Libson EG, Cahill ME, Bigio E, Berry RW, Binder LI (2007) Phosphorylation and cleavage of tau in non-AD tauopathies. Acta Neuropathol 113:513-520. https:/doi.org/10.1007/s00401-007-0209-6

37. Guo H, Albrecht S, Bourdeau M, Petzke T, Bergeron C, LeBlanc AC (2004) Active caspase- 6 and caspase-6-cleaved tau in neuropil threads, neuritic plaques, and neurofibrillary tangles of Alzheimer's disease. Am J Pathol 165: 523-531. https://doi.org/10.1016/S0002-9440(10)63317-2

38. Hanger DP, Wray S (2010) Tau cleavage and tau aggregation in neurodegenerative disease. Biochem Soc Trans 38:1016-1020. https://doi. org/10.1042/BST0381016

39. Hanseeuw BJ, Betensky RA, Jacobs HIL, Schultz AP, Sepulcre J, Becker JA, Cosio DMO, Farrell M, Quiroz YT, Mormino EC et al (2019) Association of Amyloid and Tau With Cognition in Preclinical Alzheimer Disease: A Longitudinal Study. JAMA Neurol. https://doi.org/10.1001/jamaneurol.2019.1424

40. Himmler A, Drechsel D, Kirschner MW, Martin DW Jr (1989) Tau consists of a set of proteins with repeated C-terminal microtubule-binding domains and variable N-terminal domains. Mol Cell Biol 9:1381-1388

41. Hong M, Zhukareva V, Vogelsberg-Ragaglia V, Wszolek Z, Reed L, Miller BI, Geschwind DH, Bird TD, McKeel D, Goate A et al (1998) Mutation-specific functional impairments in distinct tau isoforms of hereditary FTDP-17. Science 282:1914-1917

42. Horowitz PM, Patterson KR, Guillozet-Bongaarts AL, Reynolds MR, Carroll CA Weintraub ST, Bennett DA, Cryns VL, Berry RW, Binder LI (2004) Early Nterminal changes and caspase- 6 cleavage of tau in Alzheimer's disease. J Neurosci 24:7895-7902. https://doi.org/10.1523/JNEUROSCI.1988-04.2004 
43. Hutton M, Lendon CL, Rizzu P, Baker M, Froelich S, Houlden H, PickeringBrown S, Chakraverty S, Isaacs A, Grover A et al (1998) Association of missense and $5^{\prime}$-splice-site mutations in tau with the inherited dementia FTDP-17. Nature 393:702-705. https://doi.org/10.1038/31508

44. Jackson SJ, Kerridge C, Cooper J, Cavallini A, Falcon B, Cella CV, Landi A, Szekeres PG, Murray TK, Ahmed Z et al (2016) Short Fibrils Constitute the Major Species of Seed-Competent Tau in the Brains of Mice Transgenic for Human P301S Tau. J Neurosci 36:762-772. https://doi.org/10.1523/ JNEUROSCI.3542-15.2016

45. Jadhav S, Avila J, Scholl M, Kovacs GG, Kovari E, Skrabana R, Evans LD, Kontsekova E, Malawska B, de Silva R et al (2019) A walk through tau therapeutic strategies. Acta Neuropathol Commun 7:22. https://doi.org/10. 1186/s40478-019-0664-Z

46. Jicha GA, Bowser R, Kazam IG, Davies P (1997) Alz-50 and MC-1, a new monoclonal antibody raised to paired helical filaments, recognize conformational epitopes on recombinant tau. J Neurosci Res 48:128132. https://doi.org/10.1002/(sici)1097-4547(19970415)48:2<128:.aidjnr5>3.0.co;2-e

47. Kadavath $\mathrm{H}$, Hofele RV, Biernat J, Kumar S, Tepper K, Urlaub H, Mandelkow E, Zweckstetter M (2015) Tau stabilizes microtubules by binding at the interface between tubulin heterodimers. Proc Natl Acad Sci U S A 112:7501-7506. https://doi.org/10.1073/pnas.1504081112

48. Kellogg EH, Hejab NMA, Poepsel S, Downing KH, DiMaio F, Nogales E (2018) Near-atomic model of microtubule-tau interactions. Science 360: 1242-1246. https://doi.org/10.1126/science.aat1780

49. Kfoury N, Holmes BB, Jiang H, Holtzman DM, Diamond MI (2012) Transcellular propagation of Tau aggregation by fibrillar species. J Biol Chem 287:19440-19451. https://doi.org/10.1074/jbc. M112.346072

50. Kosik KS, Orecchio LD, Bakalis S, Neve RL (1989) Developmentally regulated expression of specific tau sequences. Neuron 2:1389-1397

51. Kovacech B, Novak M (2010) Tau truncation is a productive posttranslational modification of neurofibrillary degeneration in Alzheimer's disease. Curr Alzheimer Res 7:708-716

52. Lasagna-Reeves CA, Castillo-Carranza DL, Sengupta U, Guerrero-Munoz MJ, Kiritoshi T, Neugebauer V, Jackson GR, Kayed R (2012) Alzheimer brainderived tau oligomers propagate pathology from endogenous tau. Sci Rep 2:700. https://doi.org/10.1038/srep00700

53. Li X, Dong X, Wei G, Margittai M, Nussinov R, Ma B (2018) The distinct structural preferences of tau protein repeat domains. Chem Commun (Camb) 54:5700-5703. https://doi.org/10.1039/c8cc01263f

54. McEwan WA, Falcon B, Vaysburd M, Clift D, Oblak AL, Ghetti B, Goedert M, James LC (2017) Cytosolic FC receptor TRIM21 inhibits seeded tau aggregation. Proc Natl Acad Sci U S A 114:574-579. https://doi.org/10.1073/pnas.1607215114

55. McMillan P, Korvatska E, Poorkaj P, Evstafjeva Z, Robinson L, Greenup L, Leverenz J, Schellenberg GD, D'Souza I (2008) Tau isoform regulation is region- and cell-specific in mouse brain. J Comp Neurol 511:788-803. https://doi.org/10.1002/cne.21867

56. Meredith JE Jr, Sankaranarayanan S, Guss V, Lanzetti AJ, Berisha F, Neely RJ Slemmon JR, Portelius E, Zetterberg H, Blennow K et al (2013) Characterization of novel CSF Tau and ptau biomarkers for Alzheimer's disease. PLoS One 8:e76523. https:/doi.org/10.1371/journal.pone.0076523

57. Mirbaha H, Chen D, Morazova OA, Ruff KM, Sharma AM, Liu X, Goodarzi M, Pappu RV, Colby DW, Mirzaei H et al (2018) Inert and seed-competent tau monomers suggest structural origins of aggregation. Elife 7. https://doi.org/10.7554/eLife.36584

58. Miyasaka T, Watanabe A, Saito Y, Murayama S, Mann DM, Yamazaki M, Ravid R, Morishima-Kawashima M, Nagashima K, Ihara Y (2005) Visualization of newly deposited tau in neurofibrillary tangles and neuropil threads. J Neuropathol Exp Neurol 64:665-674. https://doi.org/10.1097/01.jnen.0000173890.79058.1d

59. Mondragon-Rodriguez S, Mena R, Binder LI, Smith MA, Perry G, Garcia-Sierra F (2008) Conformational changes and cleavage of tau in Pick bodies parallel the early processing of tau found in Alzheimer pathology. Neuropathol Appl Neurobiol 34: 62-75. https:/doi.org/10.1111/j.1365-2990.2007.00853x

60. Mukrasch MD, Biernat J, von Bergen M, Griesinger C, Mandelkow E, Zweckstetter M (2005) Sites of tau important for aggregation populate \{beta\}-structure and bind to microtubules and polyanions. J Biol Chem 280:24978-24986. https:/doi.org/10. 1074/jbc. M501565200

61. Nelson PT, Alafuzoff I, Bigio EH, Bouras C, Braak H, Cairns NJ, Castellani RJ, Crain BJ, Davies P, Del Tredici K et al (2012) Correlation of Alzheimer disease neuropathologic changes with cognitive status: a review of the literature. J Neuropathol Exp Neurol 71:362-381. https://doi.org/10.1097/NEN.0b013e31825018f7
62. Novak P, Cehlar O, Skrabana R, Novak M (2018) Tau Conformation as a Target for Disease-Modifying Therapy: The Role of Truncation. J Alzheimers Dis 64:S535-S546. https://doi.org/10.3233/JAD-179942

63. Perry G, Siedlak SL, Richey P, Kawai M, Cras P, Kalaria RN, Galloway PG, Scardina JM, Cordell B, Greenberg BD et al (1991) Association of heparan sulfate proteoglycan with the neurofibrillary tangles of Alzheimer's disease. J Neurosci 11:3679-3683

64. Porzig R, Singer D, Hoffmann R (2007) Epitope mapping of mAbs AT8 and Tau5 directed against hyperphosphorylated regions of the human tau protein. Biochem Biophys Res Commun 358:644-649. https://doi.org/10.1016/j.bbrc.2007.04.187

65. Rissman RA, Poon WW, Blurton-Jones M, Oddo S, Torp R, Vitek MP, LaFerla FM, Rohn TT, Cotman CW (2004) Caspase-cleavage of tau is an early event in Alzheimer disease tangle pathology. J Clin Invest 114:121-130. https://doi.org/10.1172/JCI20640

66. Ros R, Thobois S, Streichenberger N, Kopp N, Sanchez MP, Perez M, Hoenicka J, Avila J, Honnorat J, de Yebenes JG (2005) A new mutation of the tau gene, G303V, in early-onset familial progressive supranuclear palsy. Arch Neurol 62:1444-1450. https:/doi.org/10.1001/archneur.62.9.1444

67. Santacruz K, Lewis J, Spires T, Paulson J, Kotilinek L, Ingelsson M, Guimaraes A, DeTure M, Ramsden M, McGowan E et al (2005) Tau suppression in a neurodegenerative mouse model improves memory function. Science 309:476-481. https://doi.org/10.1126/science.1113694

68. Sawaya MR, Sambashivan S, Nelson R, Ivanova MI, Sievers SA, Apostol MI, Thompson M, Balbirnie M, Wiltzius JJ, Mcfarlane HT et al (2007) Atomic structures of amyloid cross-beta spines reveal varied steric zippers. Nature 447:453-457. https:// doi.org/10.1038/nature05695

69. Seeley WW, Crawford RK, Zhou J, Miller BL, Greicius MD (2009) Neurodegenerative diseases target large-scale human brain networks. Neuron 62:42-52. https://doi.org/ 10.1016/j.neuron.2009.03.024

70. Seidler PM, Boyer DR, Rodriguez JA, Sawaya MR, Cascio D, Murray K, Gonen T, Eisenberg DS (2018) Structure-based inhibitors of tau aggregation. Nat Chem 10:170-176. https://doi.org/10.1038/nchem.2889

71. Sevigny J, Chiao P, Bussiere T, Weinreb PH, Williams L, Maier M, Dunstan R, Salloway S, Chen T, Ling Y et al (2016) The antibody aducanumab reduces Abeta plaques in Alzheimer's disease. Nature 537:50-56. https:/doi.org/10.1038/nature19323

72. Soeda Y, Yoshikawa M, Almeida OF, Sumioka A, Maeda S, Osada H, Kondoh Y, Saito A, Miyasaka T, Kimura T et al (2015) Toxic tau oligomer formation blocked by capping of cysteine residues with 1,2-dihydroxybenzene groups. Nat Commun 6: 10216. https:/doi.org/10.1038/ncomms10216

73. Sperfeld AD, Collatz MB, Baier H, Palmbach M, Storch A, Schwarz J, Tatsch K, Reske S, Joosse M, Heutink P et al (1999) FTDP-17: an early-onset phenotype with parkinsonism and epileptic seizures caused by a novel mutation. Ann Neurol 46 : 708-715

74. Spillantini MG, Crowther RA, Kamphorst W, Heutink P, van Swieten JC (1998) Tau pathology in two Dutch families with mutations in the microtubule-binding region of tau. Am J Pathol 153:1359-1363. https://doi.org/10.1016/S0002-9440(10)65721-5

75. Swanson E, Breckenridge L, McMahon L, Som S, McConnell I, Bloom GS (2017) Extracellular Tau Oligomers Induce Invasion of Endogenous Tau into the Somatodendritic Compartment and Axonal Transport Dysfunction. J Alzheimers Dis 58:803-820. https://doi.org/10.3233/JAD-170168

76. Takeda S, Commins C, DeVos SL, Nobuhara CK, Wegmann S, Roe AD, Costantino I, Fan Z, Nicholls SB, Sherman AE et al (2016) Seed-competent high-molecular-weight tau species accumulates in the cerebrospinal fluid of Alzheimer's disease mouse model and human patients. Ann Neurol 80:355-367. https://doi.org/10.1002/ana. 24716

77. von Bergen M, Barghorn S, Li L, Marx A, Biernat J, Mandelkow EM, Mandelkow E (2001) Mutations of tau protein in frontotemporal dementia promote aggregation of paired helical filaments by enhancing local beta-structure. J Biol Chem 276: 48165-48174. https://doi.org/10.1074/jbc. M105196200

78. von Bergen M, Friedhoff P, Biernat J, Heberle J, Mandelkow EM, Mandelkow E (2000) Assembly of tau protein into Alzheimer paired helical filaments depends on a local sequence motif ((306) VQIMYK (311)) forming beta structure. Proc Natl Acad Sci U S A 97:5129-5134

79. Wang Y, Garg S, Mandelkow EM, Mandelkow E (2010) Proteolytic processing of tau. Biochem Soc Trans 38:955-961. https://doi.org/10.1042/BST0380955

80. Wisniewski JR, Nagaraj N, Zougman A, Gnad F, Mann M (2010) Brain phosphoproteome obtained by a FASP-based method reveals plasma membrane protein topology. J Proteome Res 9:3280-3289. https:/doi.org/10.1021/pr1002214

81. Yanamandra K, Kfoury N, Jiang H, Mahan TE, Ma S, Maloney SE, Wozniak DF, Diamond MI, Holtzman DM (2013) Anti-tau antibodies that block tau aggregate seeding in vitro markedly decrease pathology and improve cognition in vivo. Neuron 80:402-414. https://doi.org/10.1016/j.neuron.2013.07.046 
82. Zhang W, Tarutani A, Newell KL, Murzin AG, Matsubara T, Falcon B, Vidal R, Garringer HJ, Shi Y, Ikeuchi T et al (2019) Novel tau filament fold in corticobasal degeneration, a four-repeat tauopathy. BioRxiv: Doi. https//doi.org/10.1101/811703

83. Zilka N, Kovacech B, Barath P, Kontsekova E, Novak M (2012) The selfperpetuating tau truncation circle. Biochem Soc Trans 40:681-686. https:// doi.org/10.1042/BST20120015

\section{Publisher's Note}

Springer Nature remains neutral with regard to jurisdictional claims in published maps and institutional affiliations.

Ready to submit your research? Choose BMC and benefit from:

- fast, convenient online submission

- thorough peer review by experienced researchers in your field

- rapid publication on acceptance

- support for research data, including large and complex data types

- gold Open Access which fosters wider collaboration and increased citations

- maximum visibility for your research: over $100 \mathrm{M}$ website views per year

At BMC, research is always in progress.

Learn more biomedcentral.com/submissions 